\title{
The contribution of wood burning and other pollution sources to winter- time organic aerosol levels in two Greek cities
}

\section{Kalliopi Florou et al.}

Correspondence to: Spyros N. Pandis (spyros@chemeng.upatras.gr)

The copyright of individual parts of the supplement might differ from the CC-BY 3.0 licence. 


\section{Location of sampling sites}
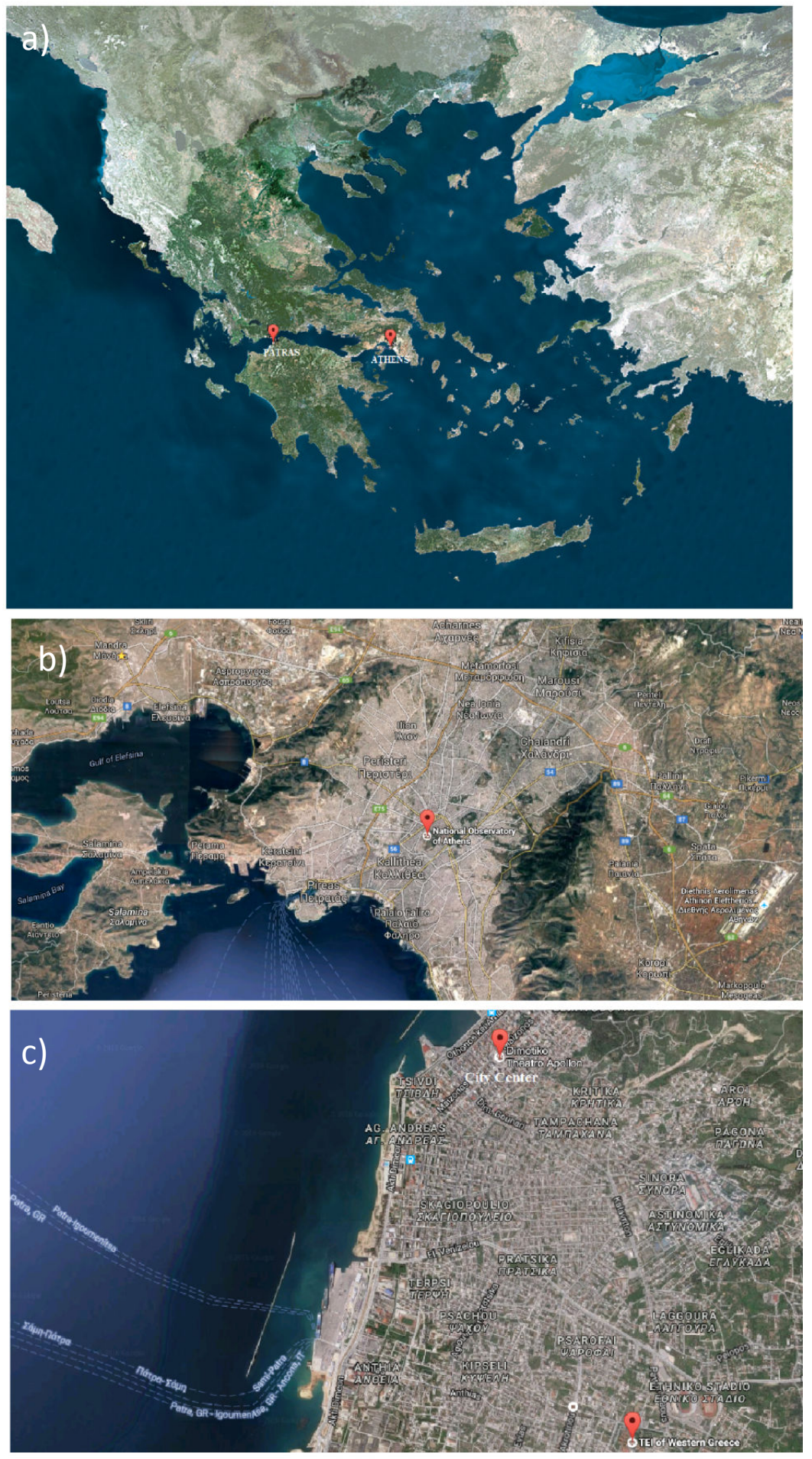

Figure S1. The location of the sampling sites: (a) the cities of Patras and Athens in Greece; (b) the National Observatory (Thiseio) in Athens; and (c) the Technological Educational Institute (TEI) and the city center of Patras. 


\section{Origin of air masses in Patras}

\section{2}

\begin{tabular}{r|r|r|r|r|r|r|r|r|r|r|}
\hline & $25 / 02$ & $26 / 02$ & $27 / 02$ & $28 / 02$ & $29 / 02$ & $01 / 03$ & $02 / 03$ & $03 / 03$ & $04 / 03$ & $05 / 03$ \\
\hline $00: 00$ & & & & & & & & & & \\
\hline $03: 00$ & & & & & & & & & \\
\hline $06: 00$ & & & & & & & & & \\
\hline $09: 00$ & & & & & & & & & \\
\hline $12: 00$ & & & & & & & & & \\
\hline $15: 00$ & & & & & & & & & \\
\hline $18: 00$ & & & & & & & & & \\
\hline $21: 00$ & & & & & & & & & & \\
\hline
\end{tabular}

Western Greece

Marine/Italy

Central Greece/ Balkans

Figure S2. FLEXPART analysis for the Patras campaign. The origin of the air mass every $3 \mathrm{~h}$ for all the sampling days is shown.
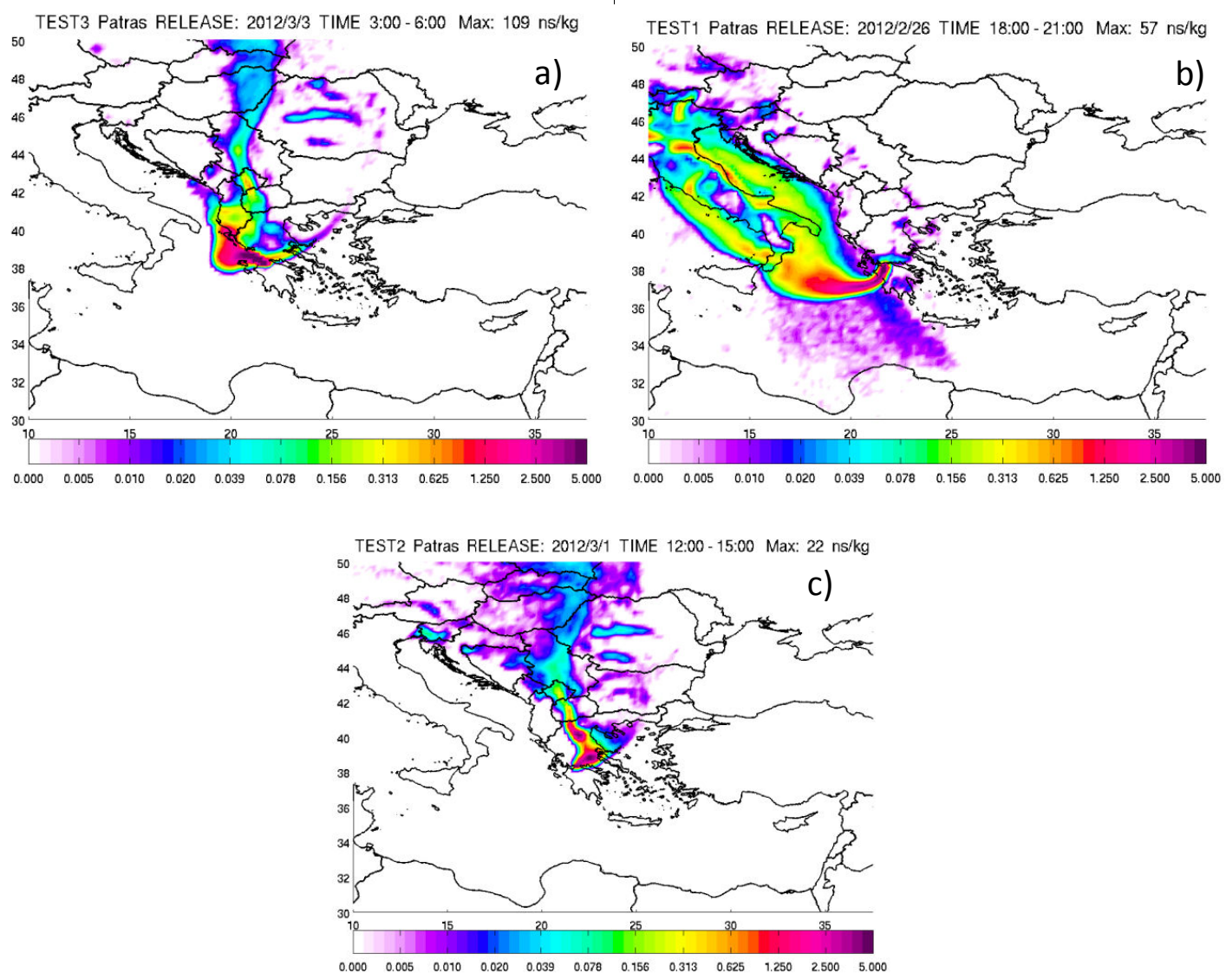

Figure S3. Examples of the three categories of back-trajectories of air masses arriving in Patras: a) western Greece; b) marine/Italy; and c) central Greece/Balkans. 


\section{Origin of air masses in Athens}
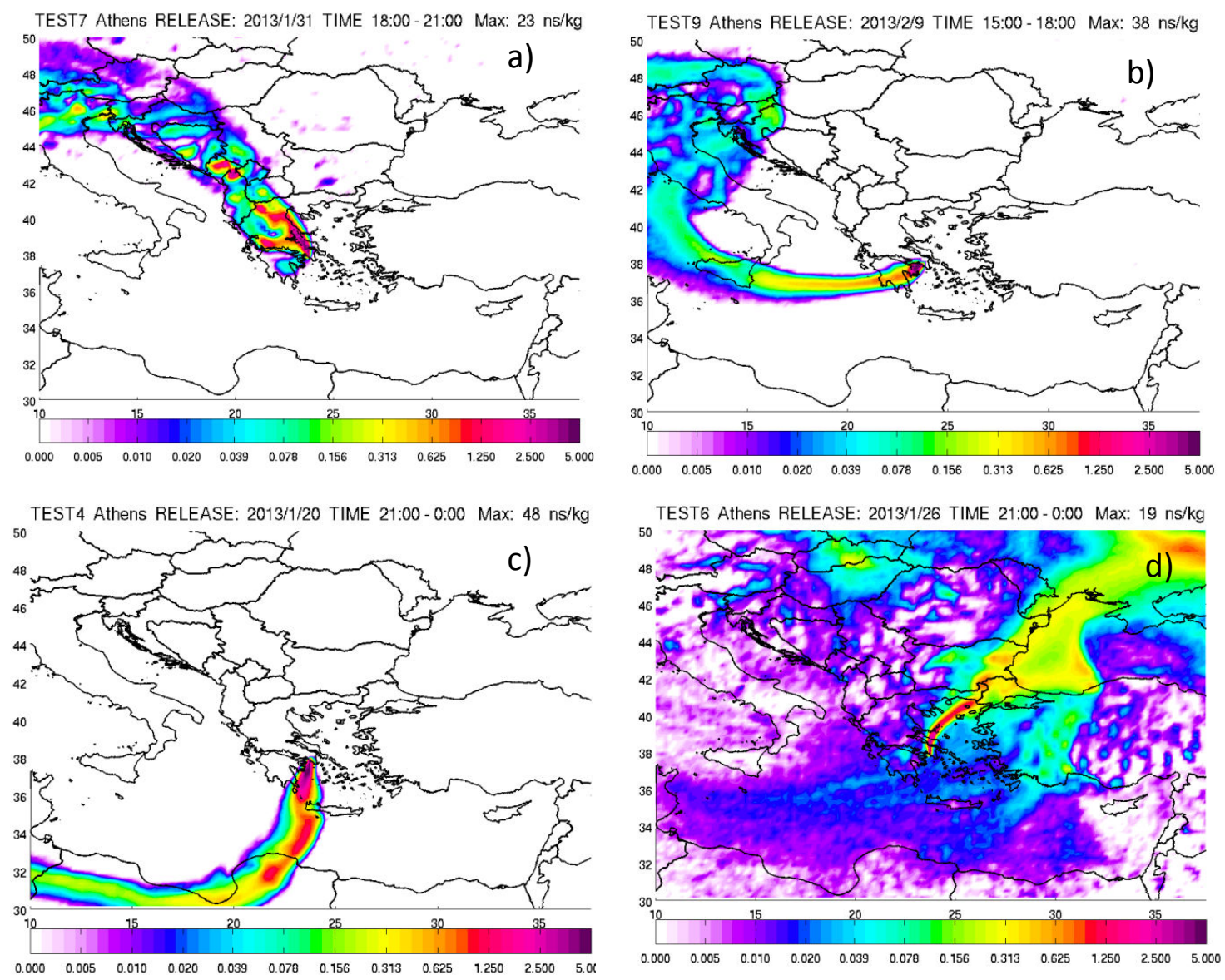

Figure S4. Examples of the three categories of back-trajectories of air masses arriving in Athens: (a) Greece-Balkans; (b) marine (Sicily); (c) Africa and (d) Aegean/NE.

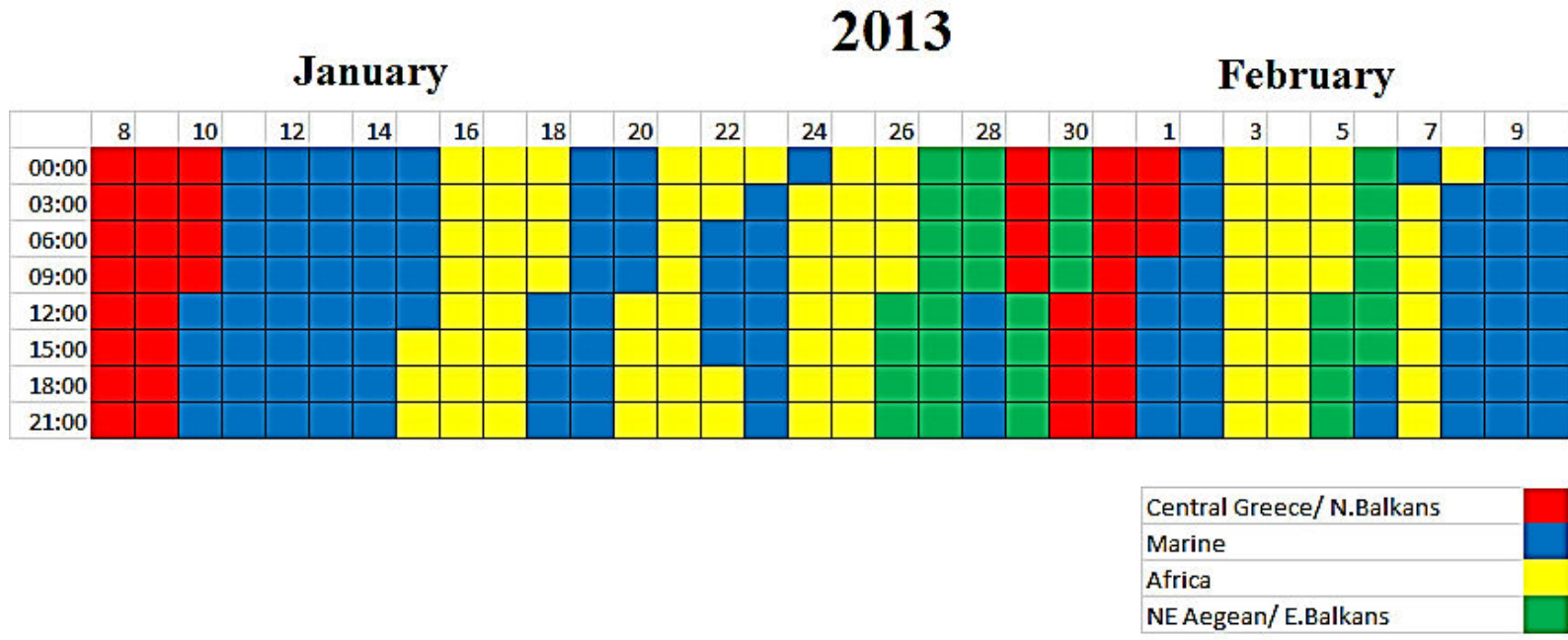

Figure S5. FLEXPART analysis for the Athens campaign. The origin of the air mass every $3 \mathrm{~h}$ for all the sampling days is shown. 


\section{4. $\quad$ Rain events in Athens}

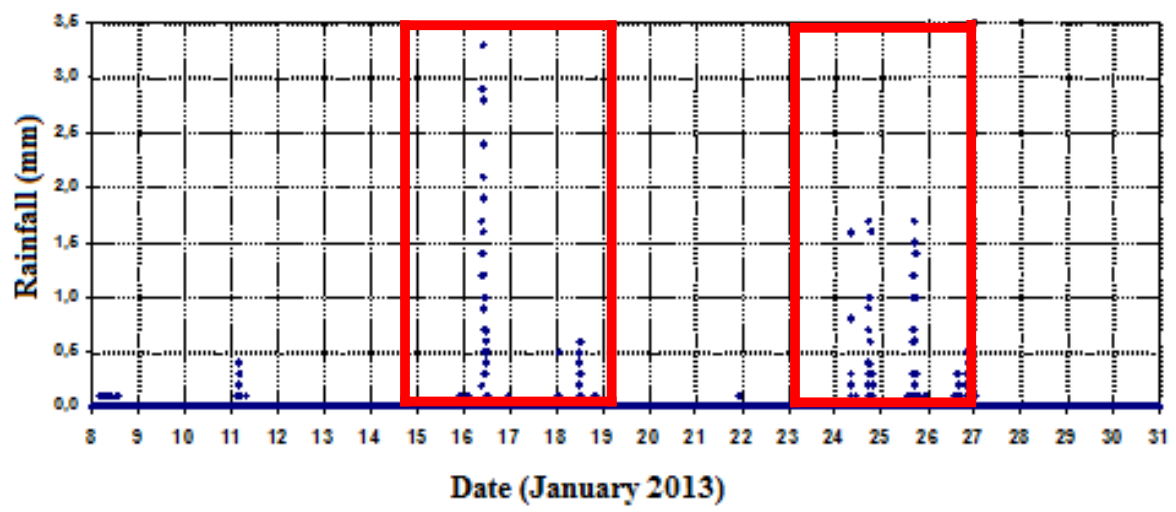

Figure S6. Cumulative precipitation at 5-min intervals in the center of Athens during January 2013. The red boxes show the two periods with frequent precipitation. 


\section{5. $\quad$ Average AMS size distributions}

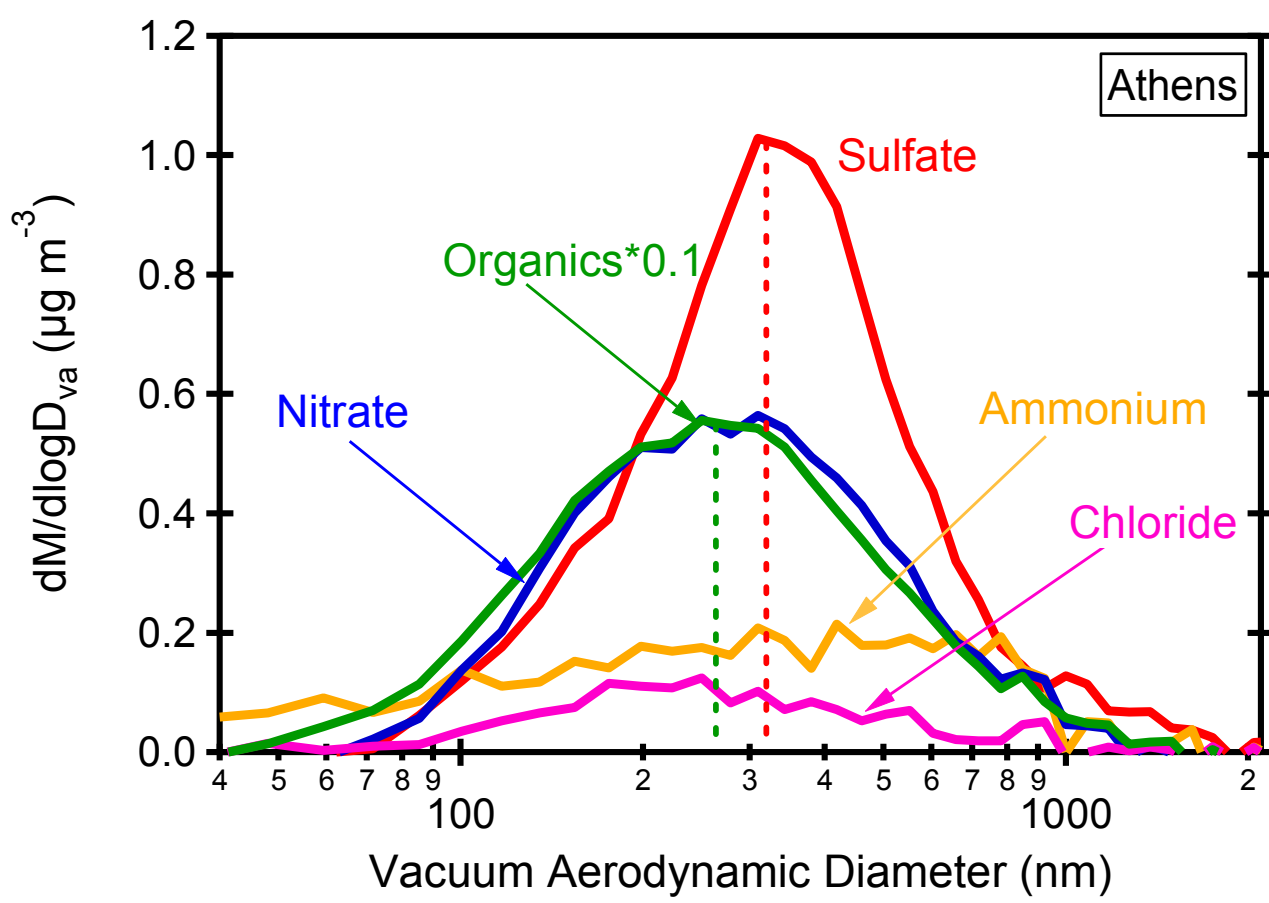

(a)

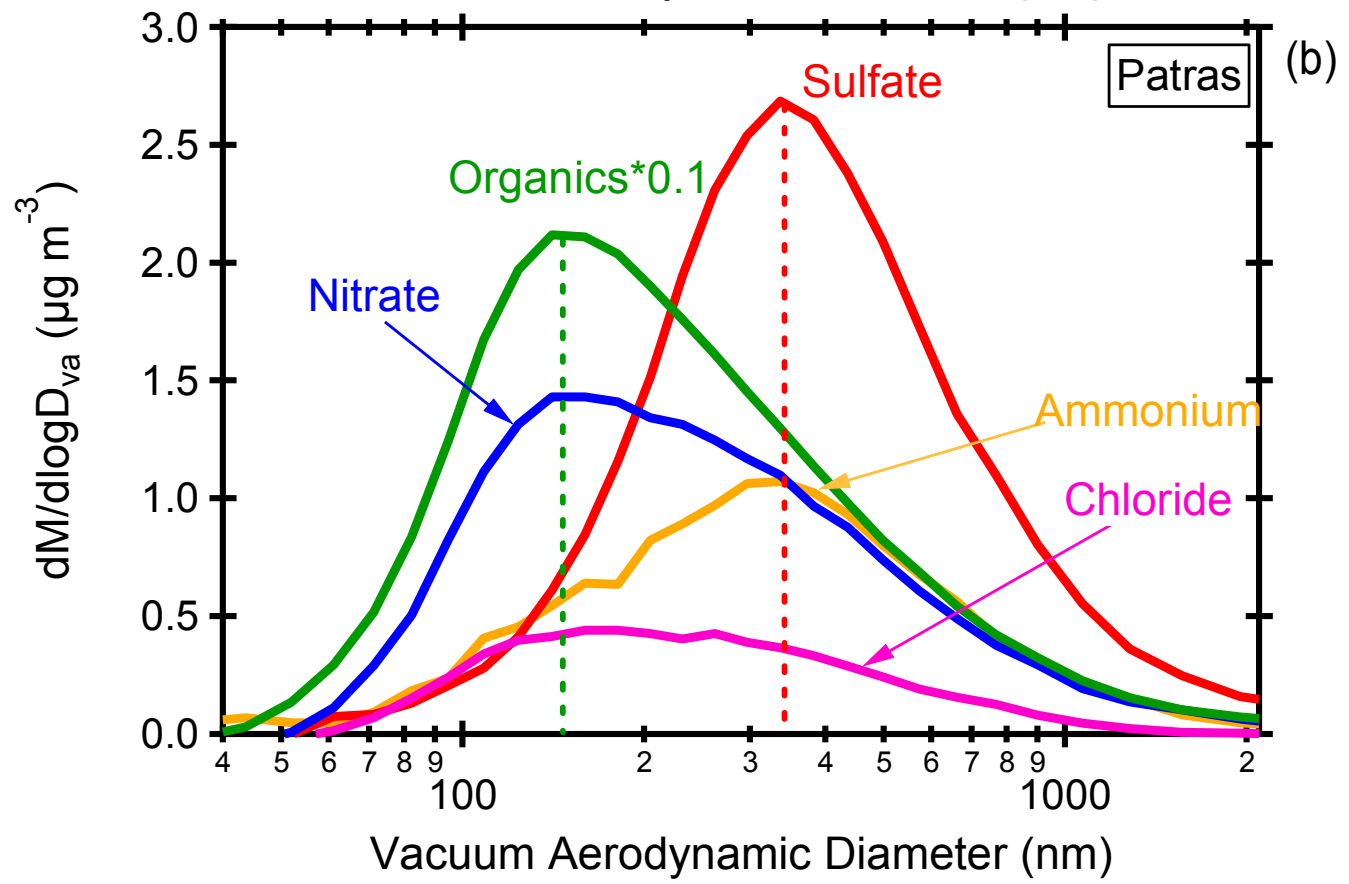

Figure S7. The average HR-AMS size distributions as a function of vacuum aerodynamic diameter for: (a) Athens and (b) Patras. The mean mode of the size distribution of the organics $(140 \mathrm{~nm})$ and sulfate $(330 \mathrm{~nm})$ are marked with dashed lines (green and red, respectively). 


\section{Elemental ratios and carbon oxidation state $\left(\mathrm{OS}_{\mathrm{C}}\right)$}

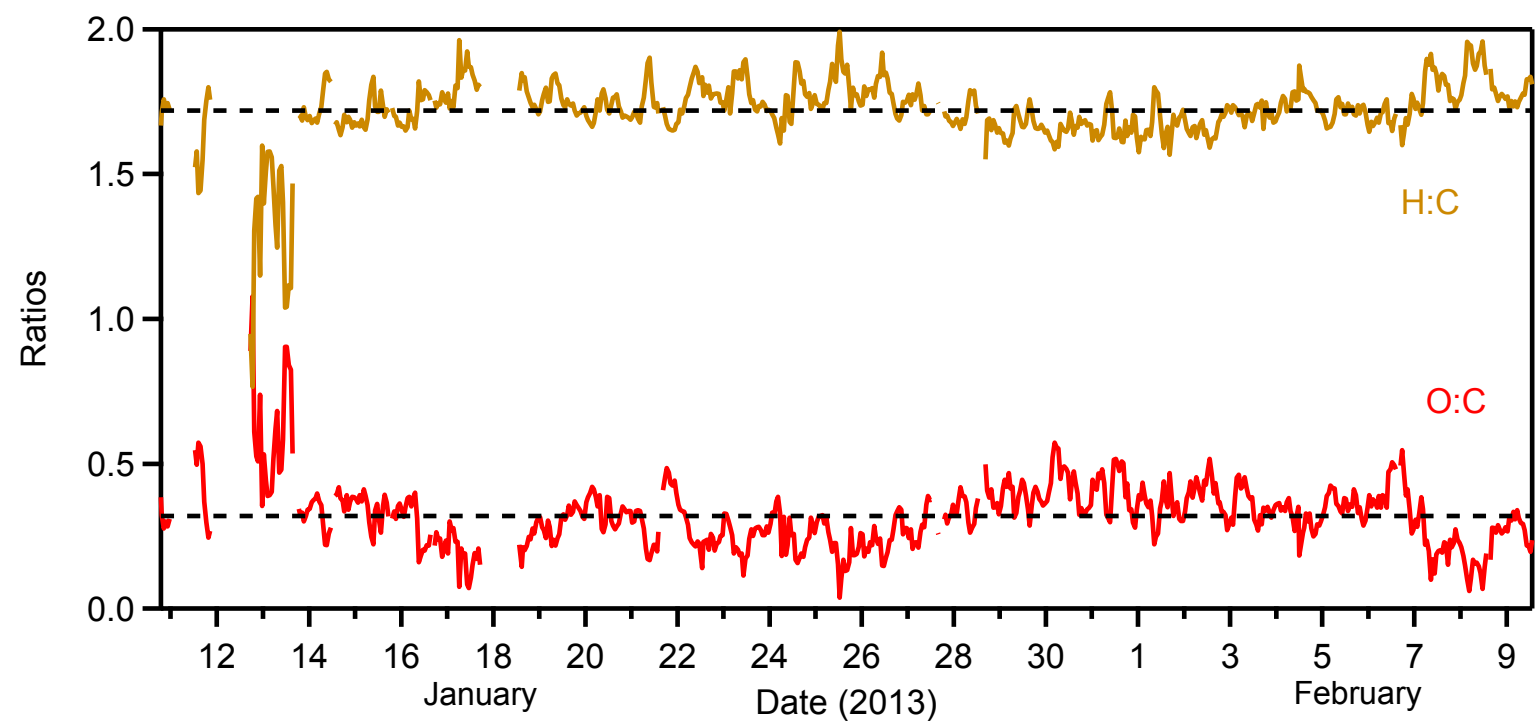

a)

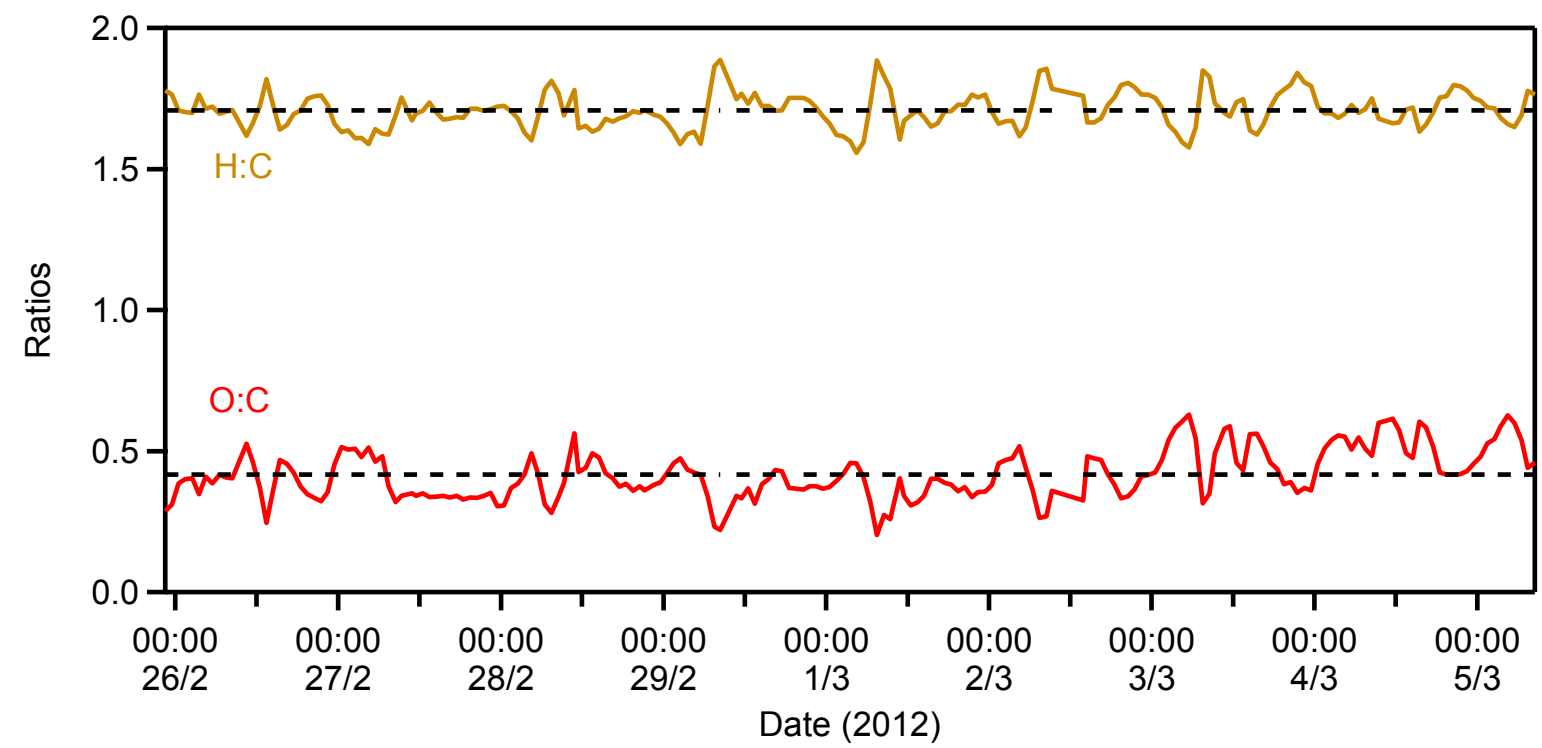

b)

Figure S8. Time series of the OA O:C and H:C ratios for: a) Athens and b) Patras based on the approach of Canagaratna et al. (2015). Their mean values are shown with dashed lines. 


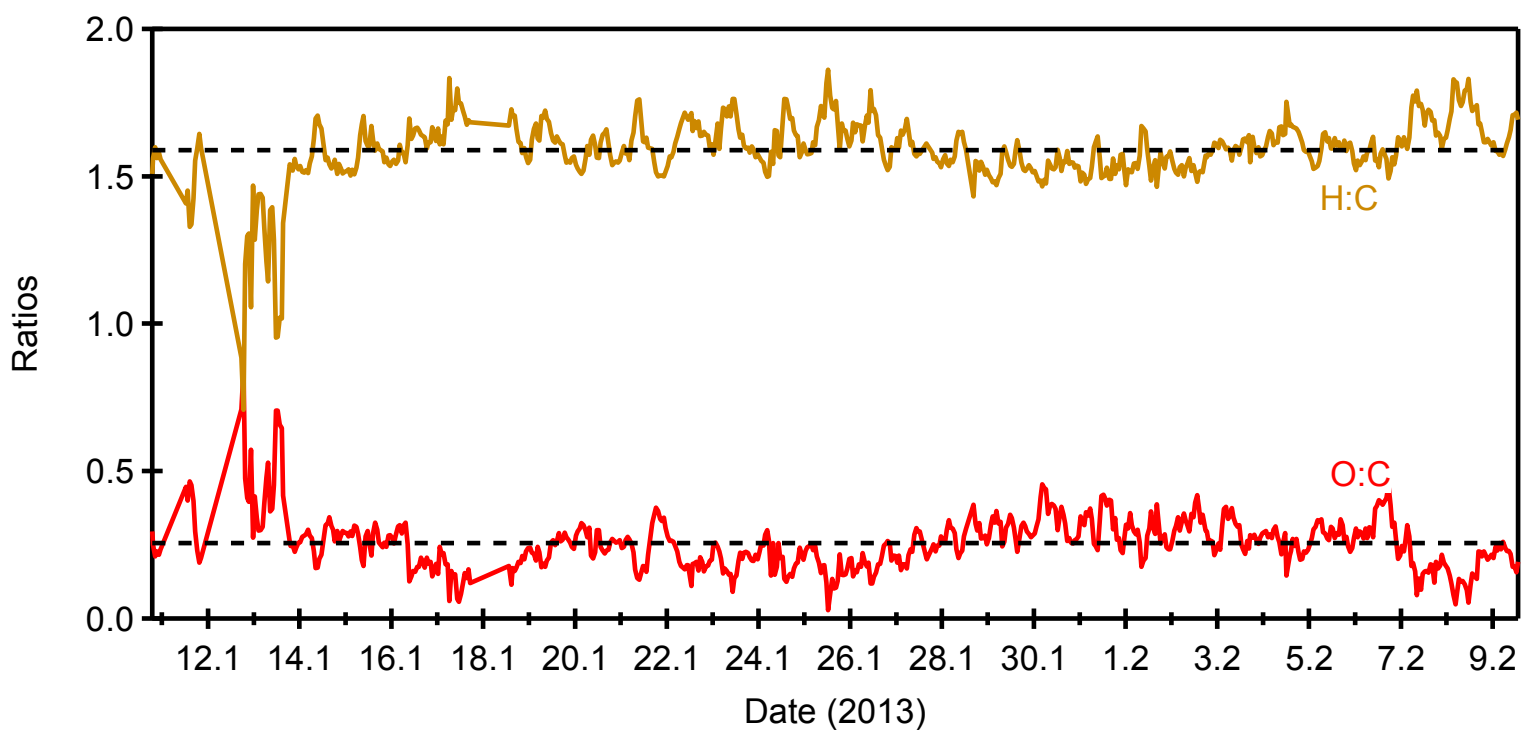

a)

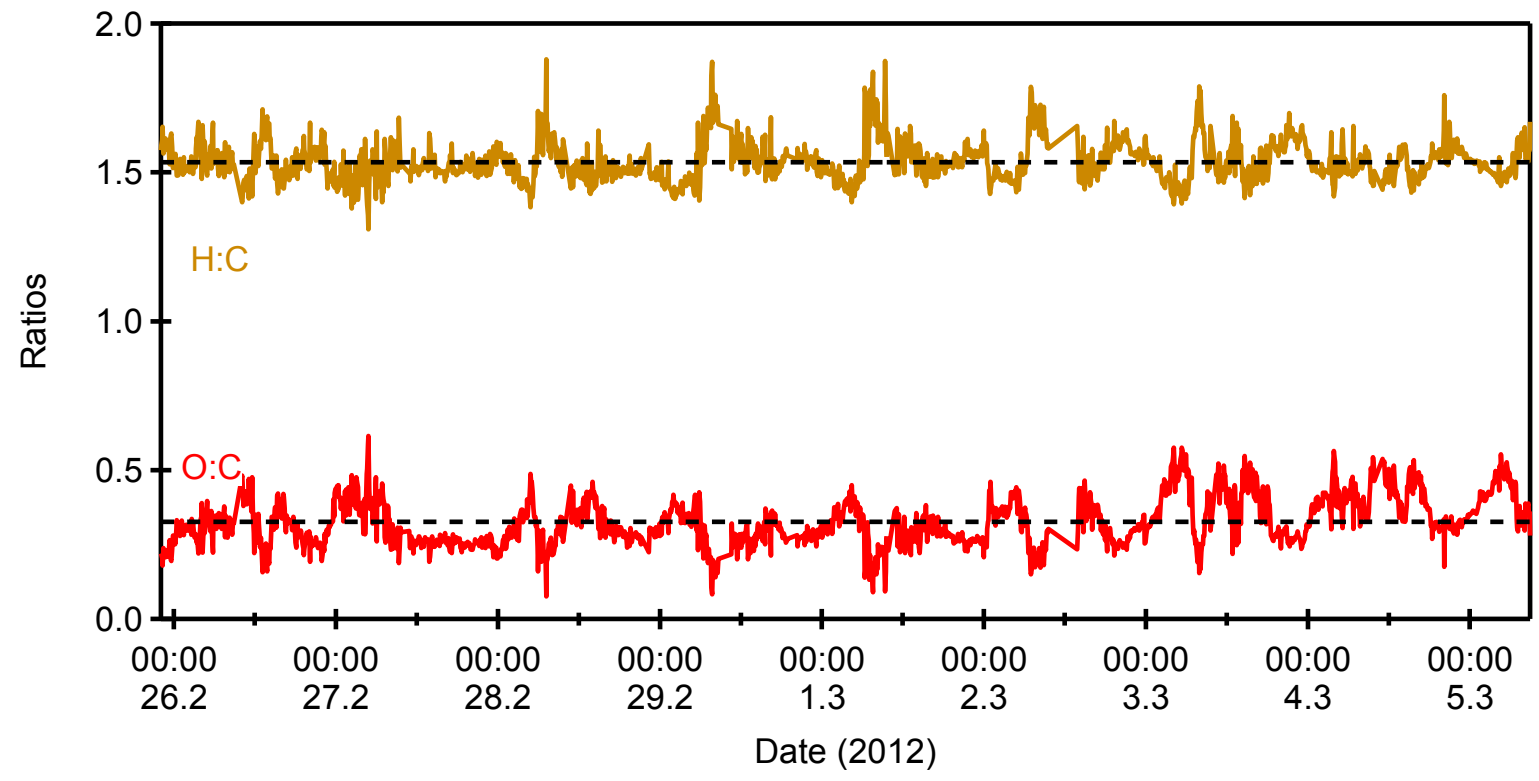

b)

Figure S9. O:C and H:C elemental ratios in: a) Athens and b) Patras based on the approach of Aiken et al. (2008). Their mean value is shown with dashed lines. 

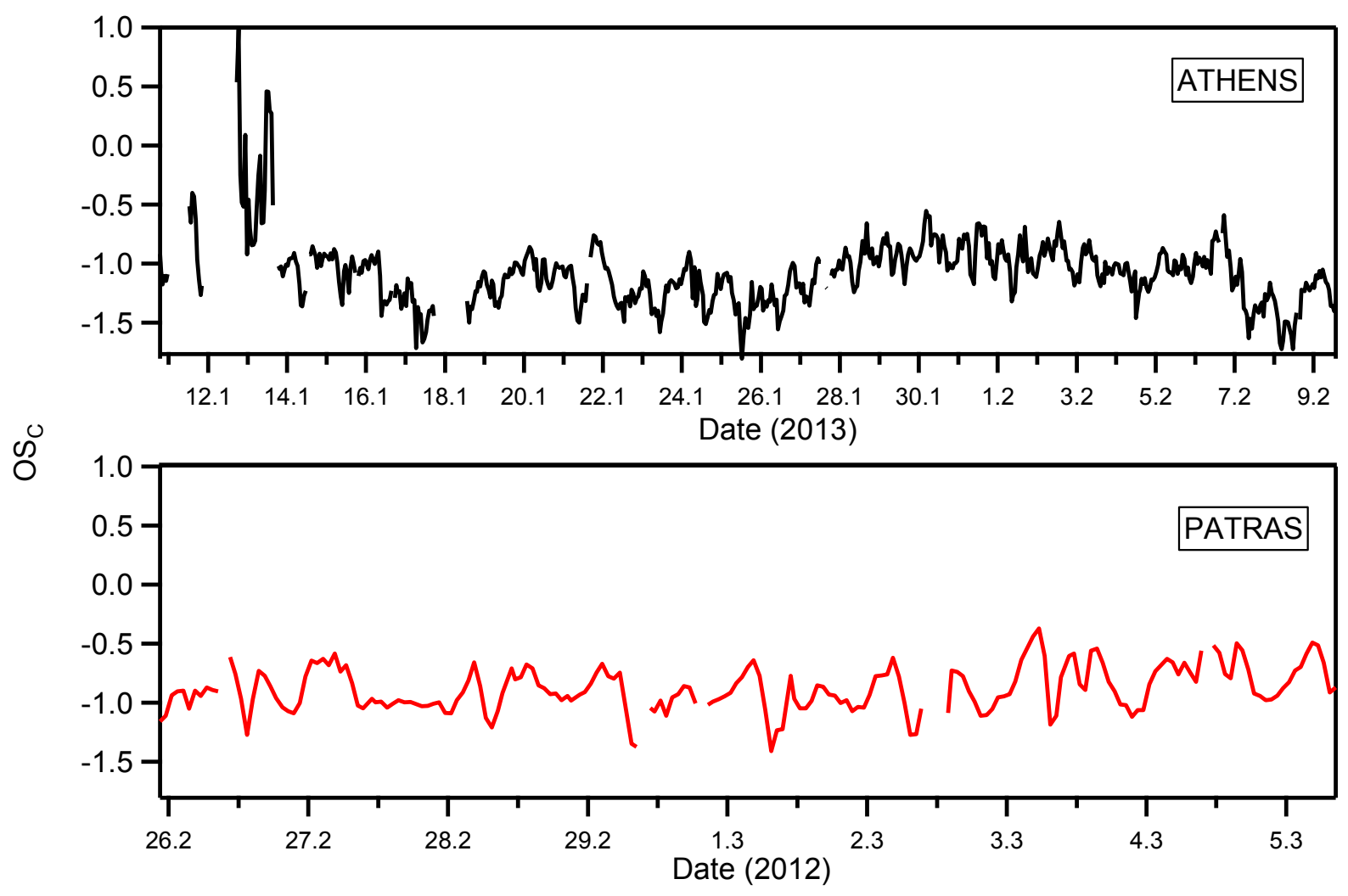

Figure S10. Average carbon oxidation state $\mathrm{OS}_{C}$ for the two cities. 

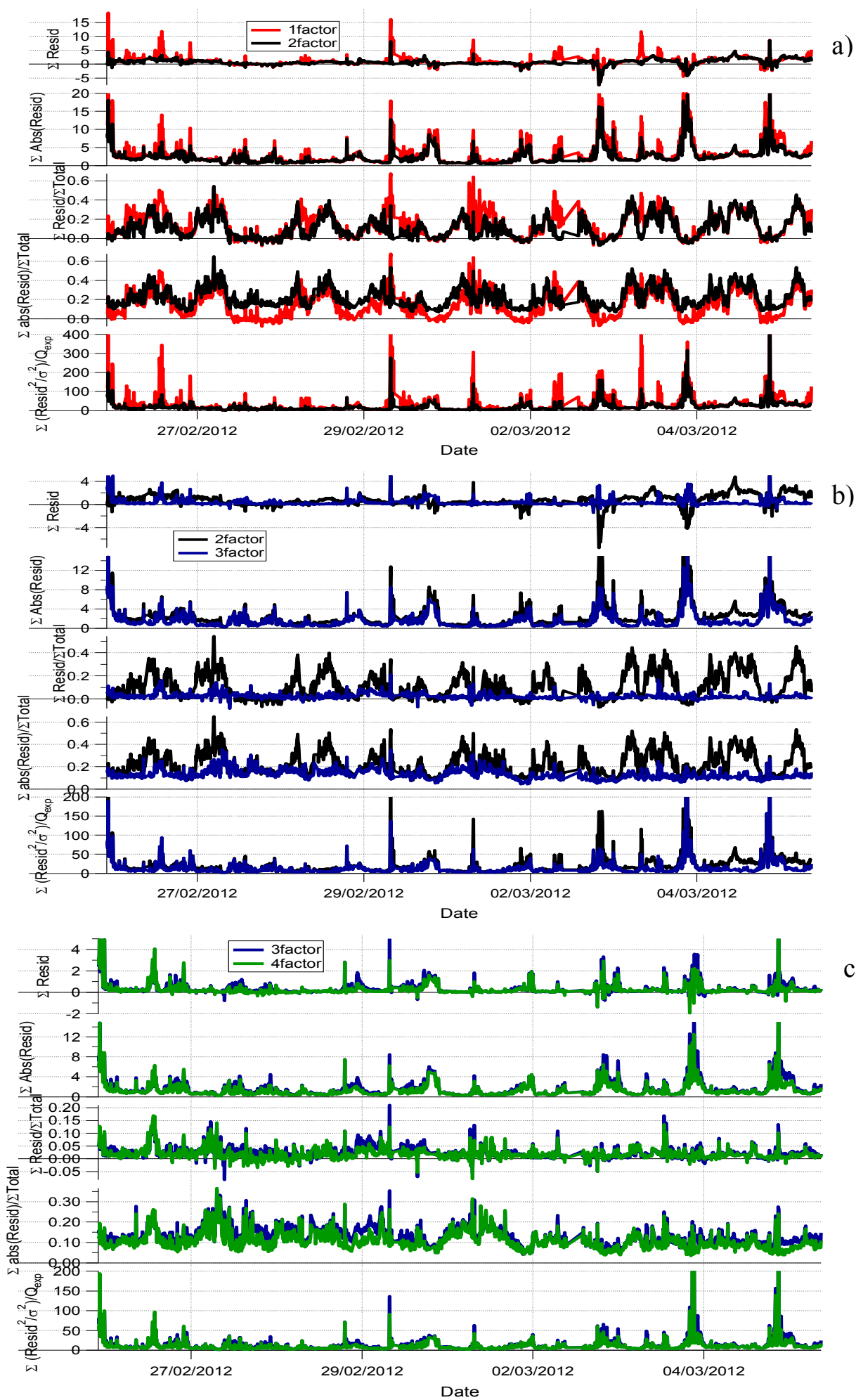

Figure S11. Model residuals $\mathbf{E}=\mathbf{X}-\mathbf{G F}$ calculated using the PMF evaluation tool PET (Ulbrich et al., 2009) for Patras. Comparison between (a) 1-factor (red lines) and 2-factor (black lines) PMF solutions, (b) 2-factor (black lines) and 3-factor (blue lines) PMF solutions, and (c) 3-factor (blue lines) and 4-factor (green lines) PMF solutions. 

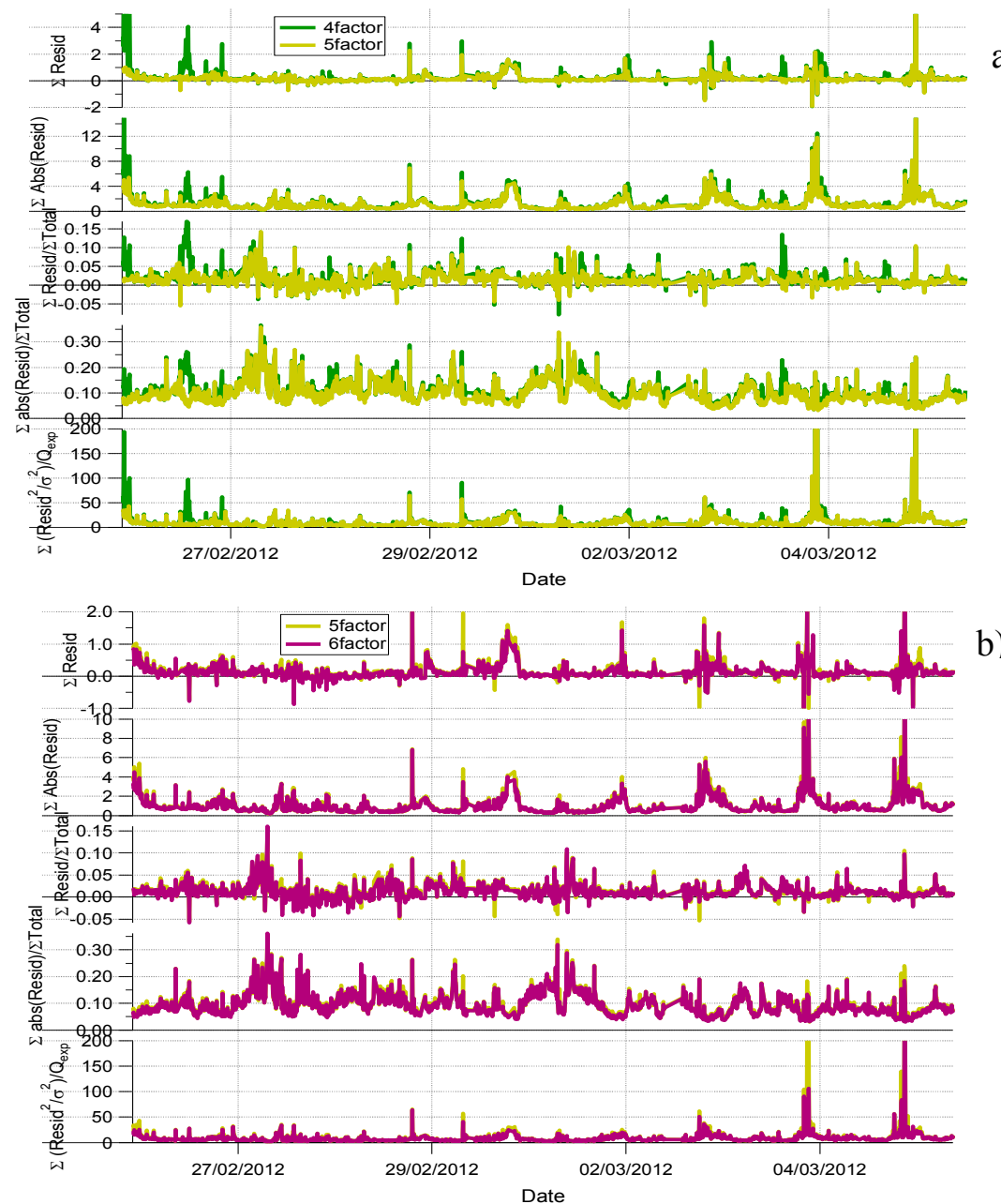

b)

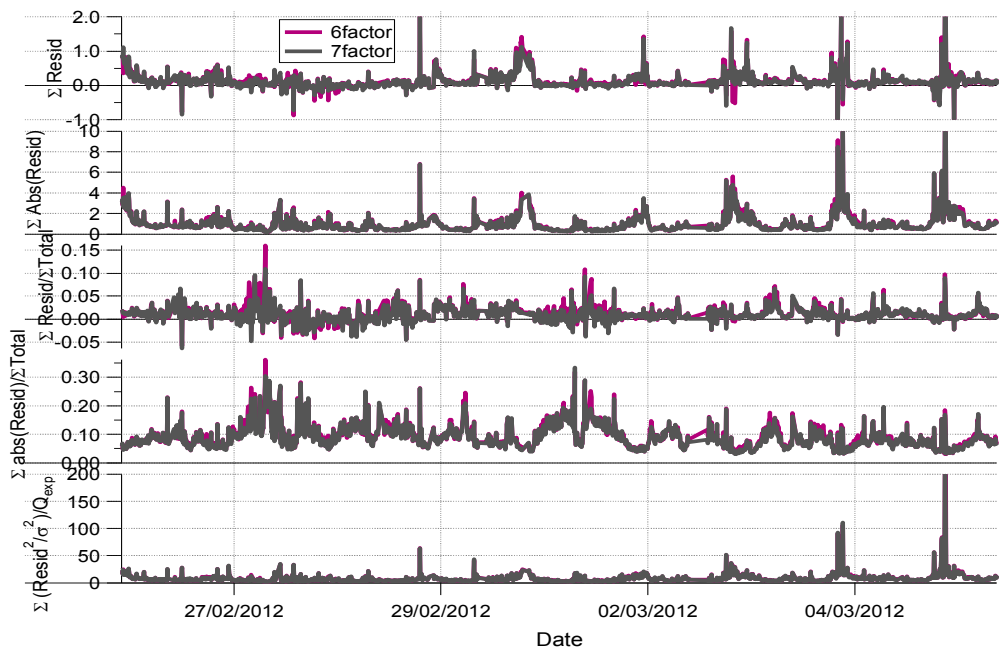

Figure S12. Model residuals $\mathbf{E}=\mathbf{X}-\mathbf{G F}$ calculated using the PMF evaluation tool PET (Ulbrich et al., 2009) for Patras. Comparison between a) 4-factor (green lines) and 5-factor (yellow lines) solutions, (b) 5-factors (yellow lines) and 6-factors (pink lines), and (c) 6factors (pink lines) and 7-factors (grey lines) PMF solutions. The residuals decreased from 4 to 5 factors especially for the first days of the campaign and March 4. The 5, 6 and 7 factor solution residuals were almost identical. 


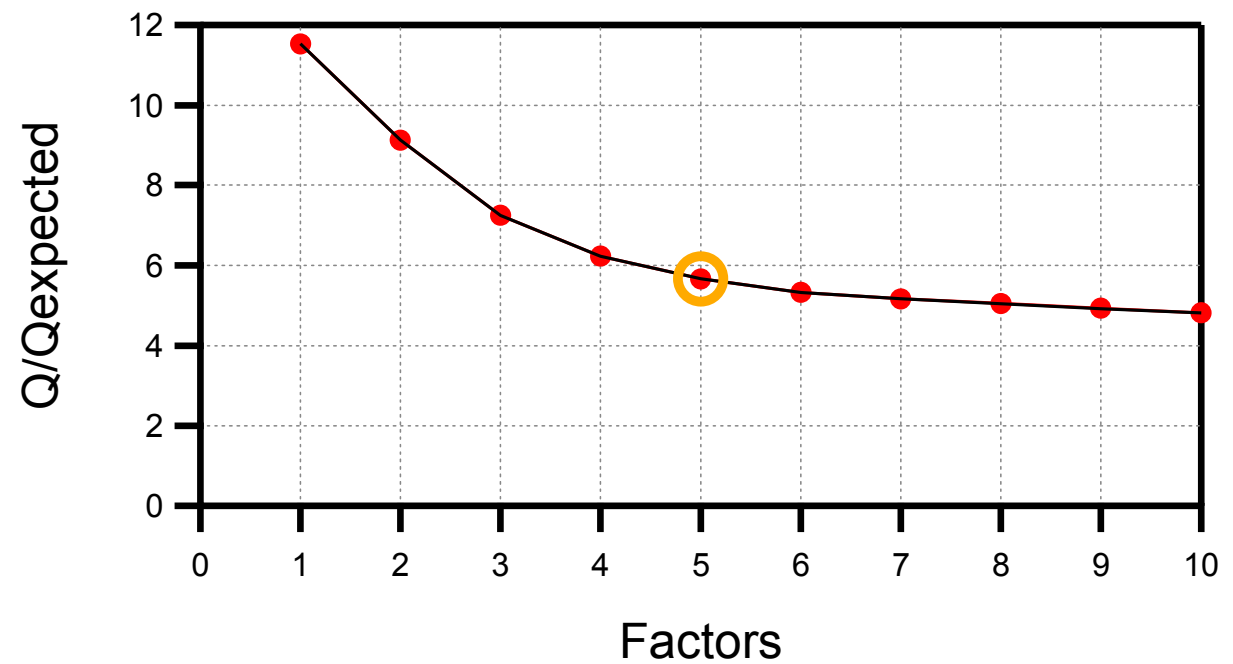

Figure S13. Q/Qexpected Vs. the number of the factors in Patras.

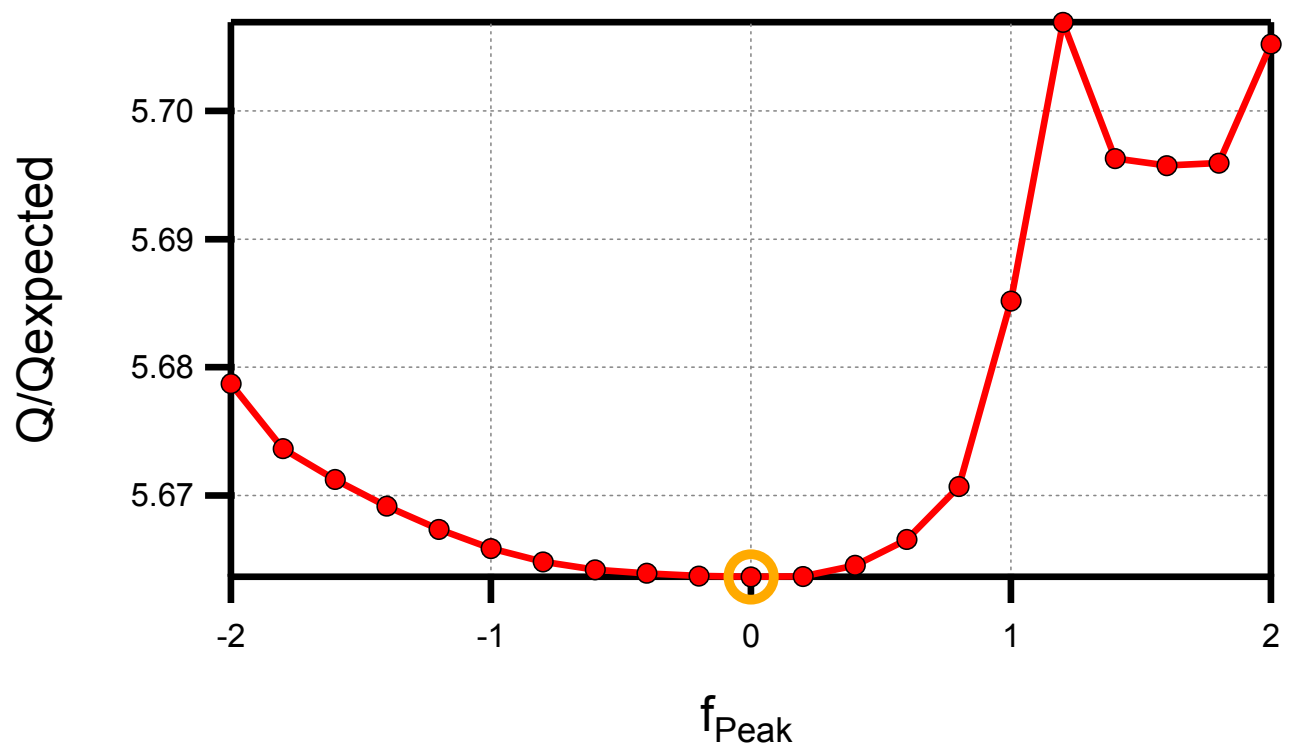

Figure S14. Q/Q $\mathrm{Q}_{\text {expected }}$ for $f_{\text {peak }}-2$ to 2 for the 5 -factor solution in Patras. There is a stable area between $\mathrm{f}_{\text {peak }}-0.6$ and 0.2 , with the lower $\mathrm{Q} / \mathrm{Q}$ expected at $f_{\text {peak }}=0.0$ and $f_{\text {peak }}=0.2$. 

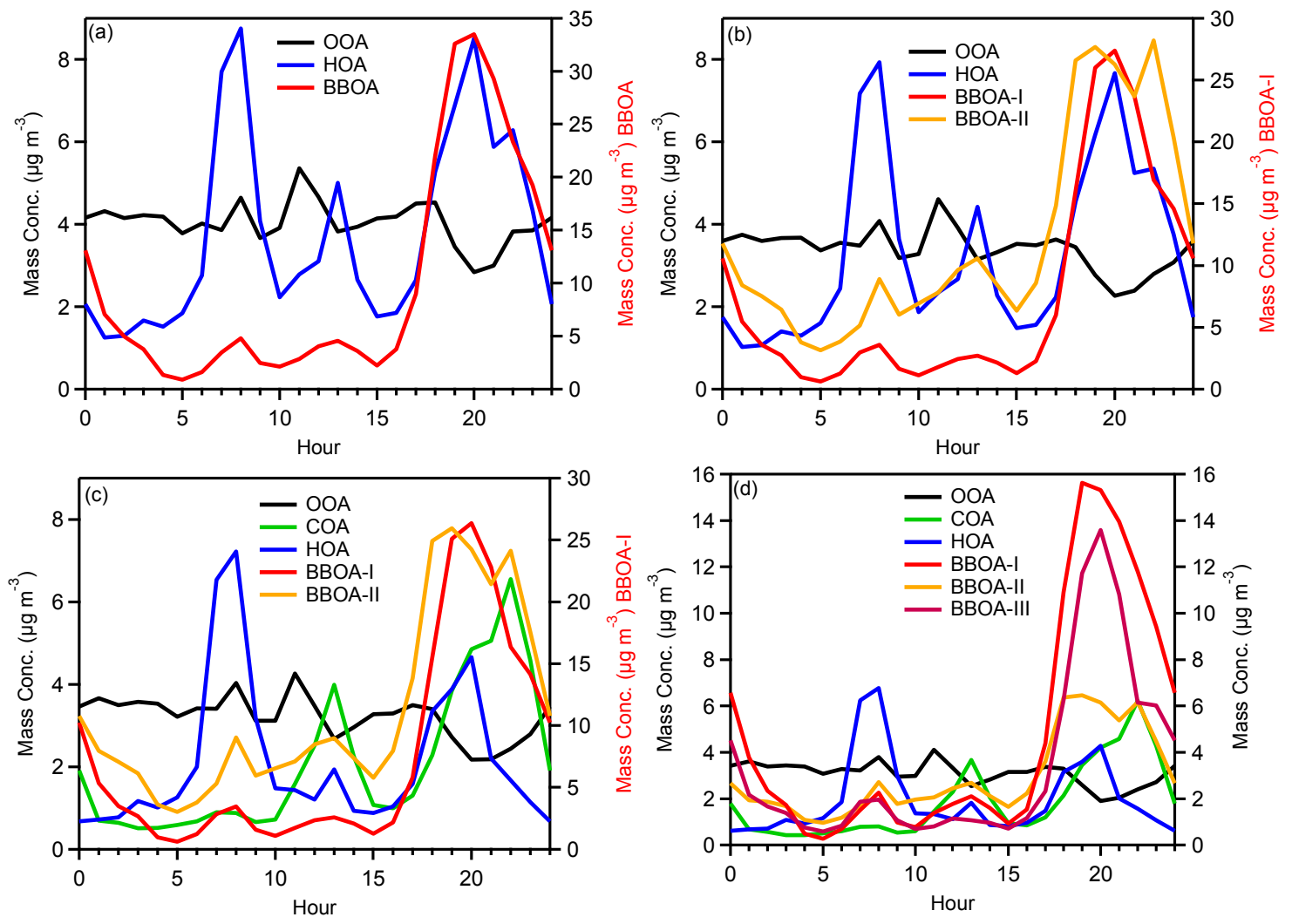

Figure S15. Average diurnal profiles of the mass concentration for the: (a) 3, (b) 4, (c) 5 and (d) 6 factor PMF solutions in Patras. 


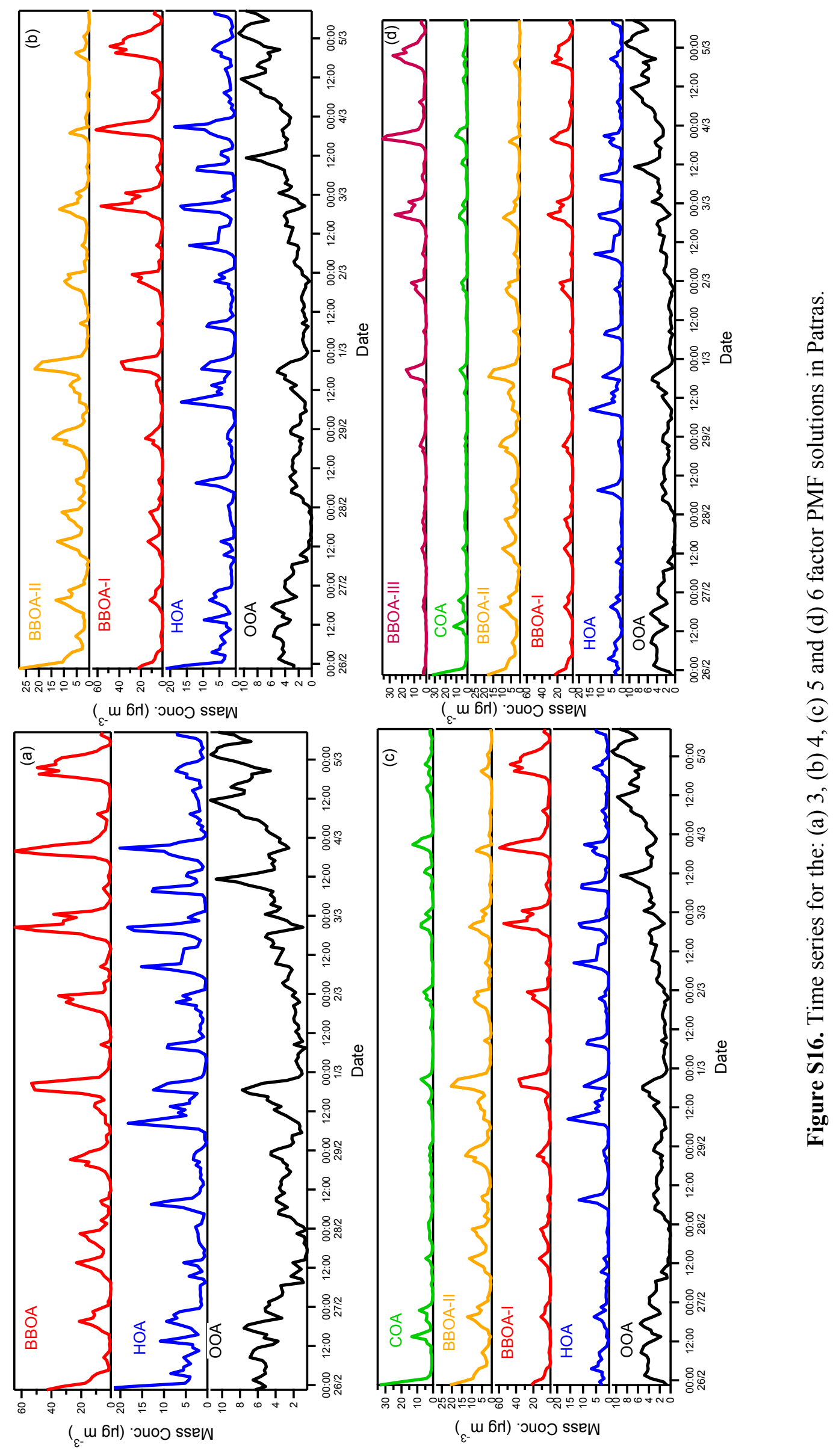

孛 


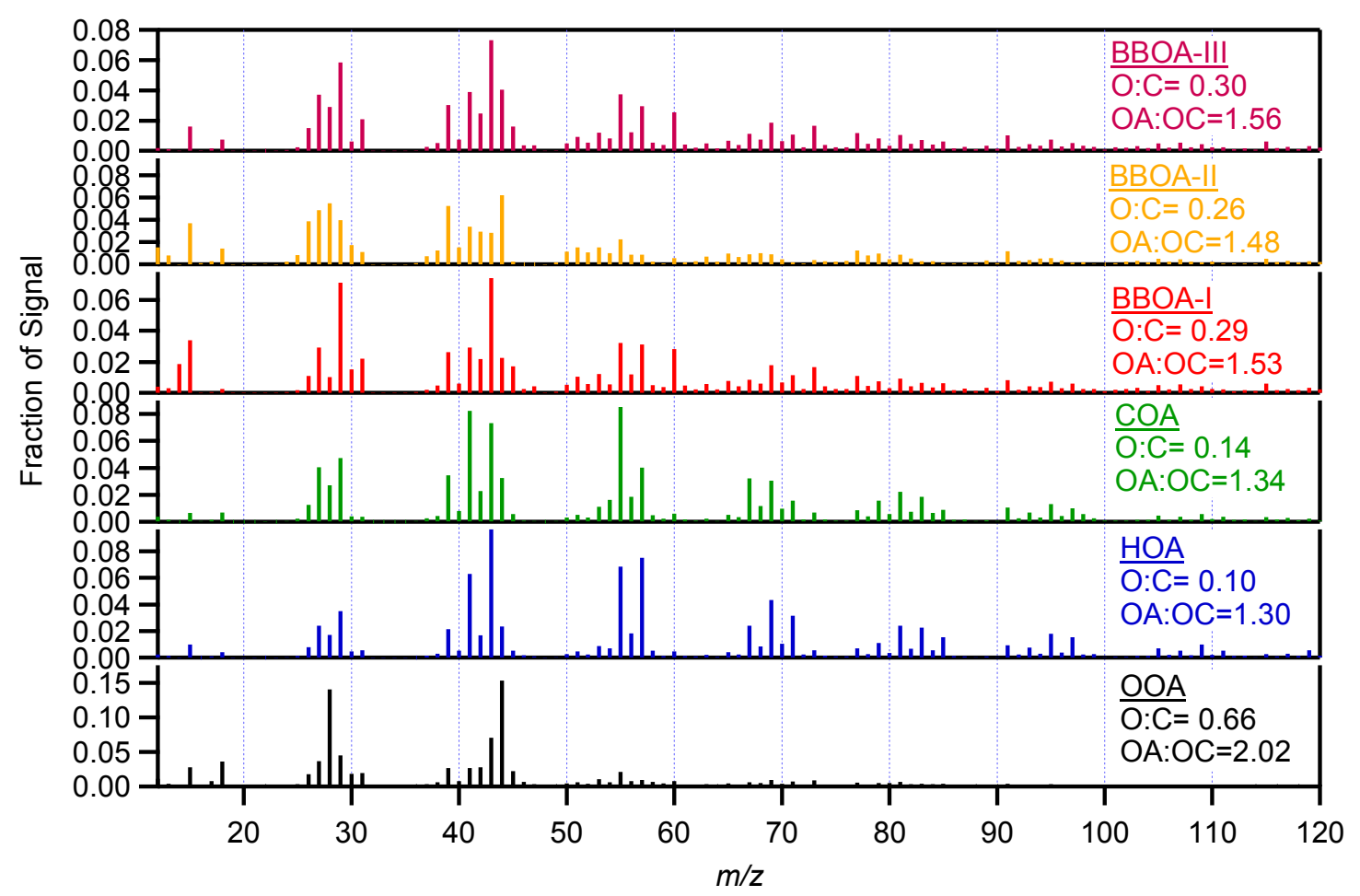

a)

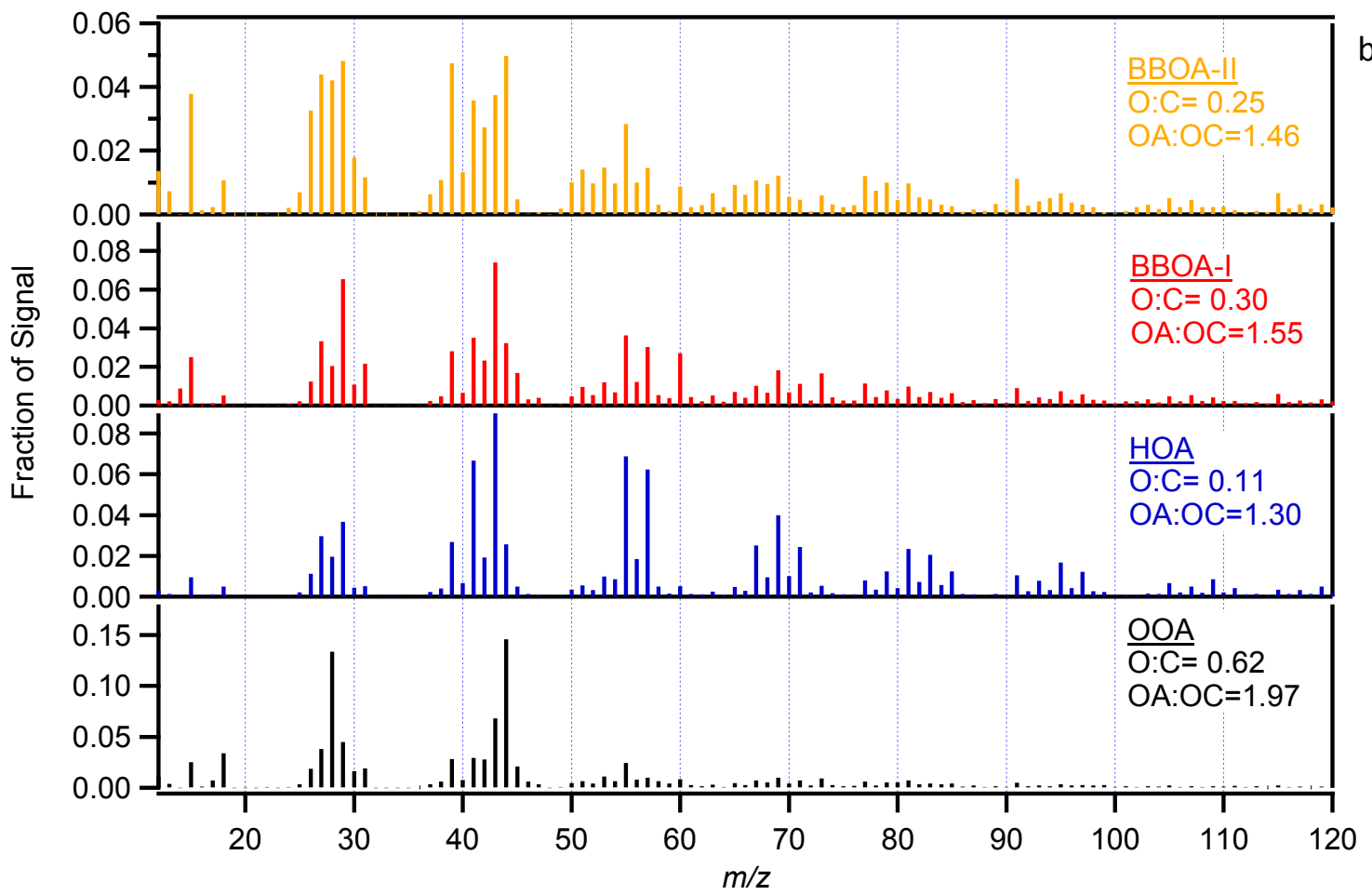




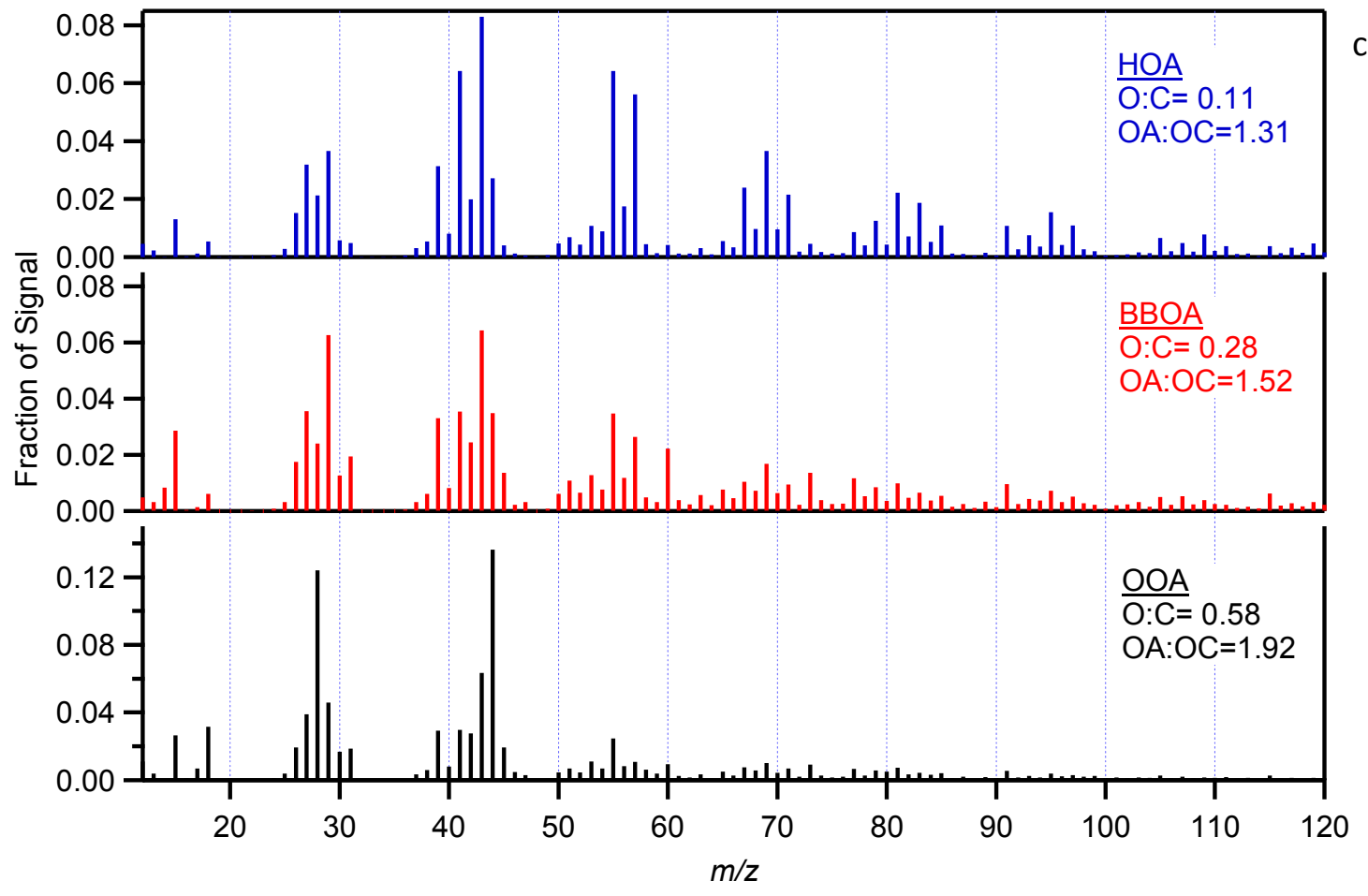

Figure S17. AMS spectra for the (a) 6, (b) 4 and (c) 3-factor PMF solutions in Patras. 

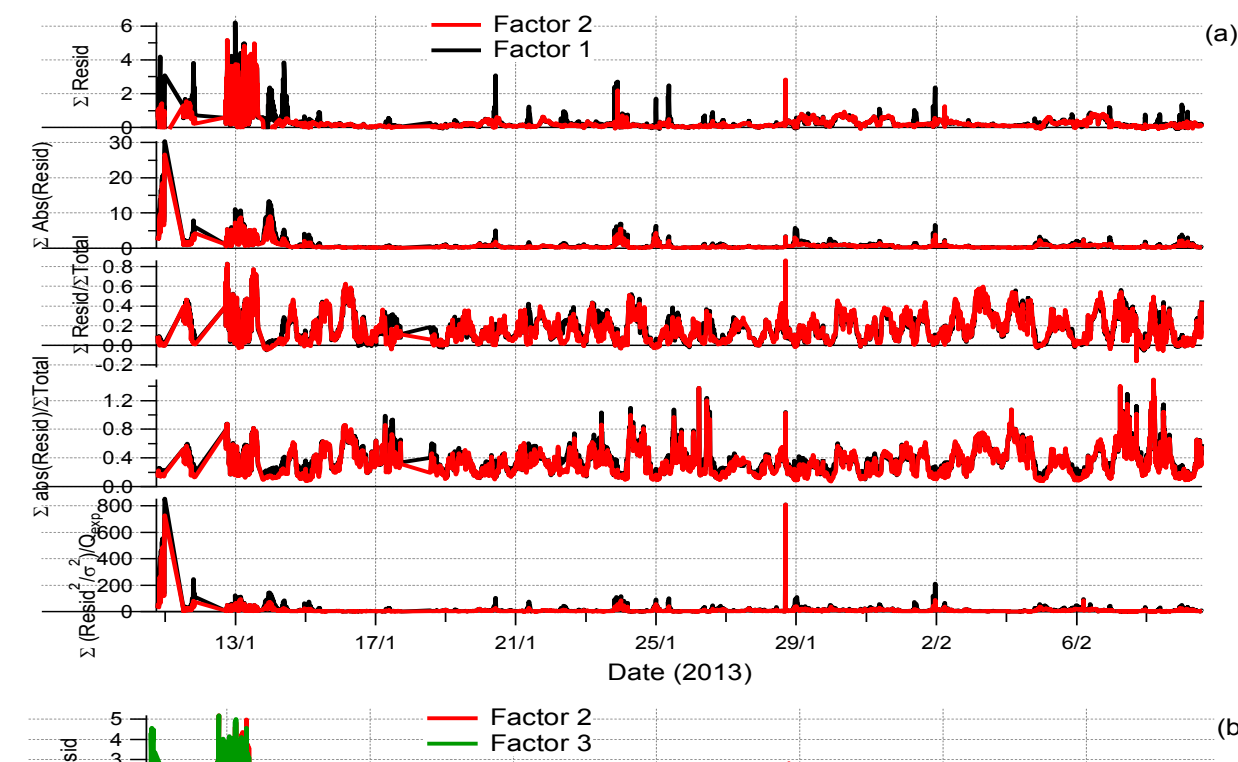

(b)
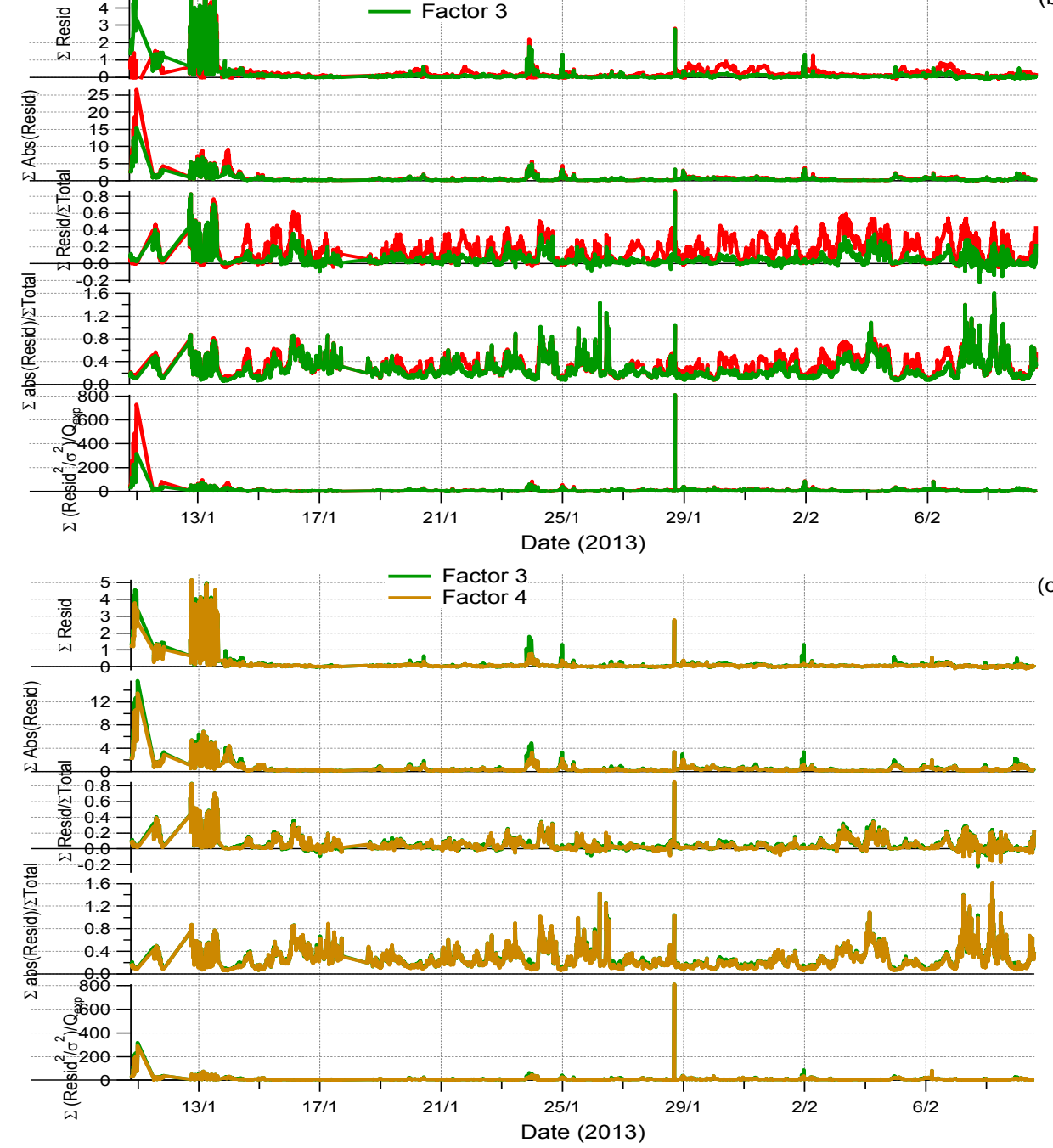

Figure S18. Model residuals $\mathbf{E}=\mathbf{X}-\mathbf{G F}$ calculated using the PMF evaluation tool, PET (Ulbrich et al., 2009) for Athens. Comparison between (a) 1-factor (black lines) and 2-factor (red lines) PMF solutions, (b) 2-factor (red lines) and 3-factor (green lines) PMF solutions, and (c) 3-factor (green lines) and 4-factor (yellow lines) PMF solutions. 


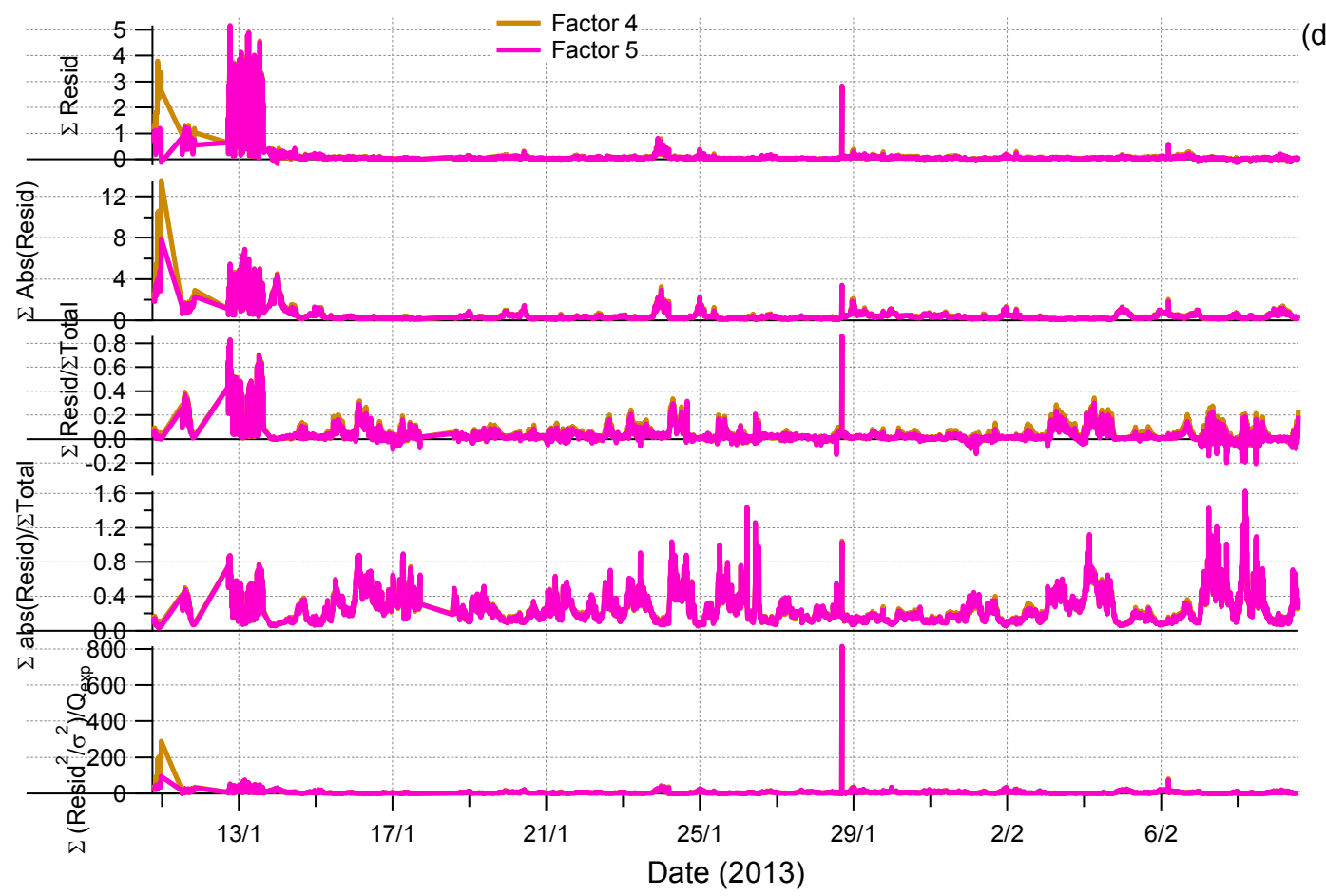

(d)

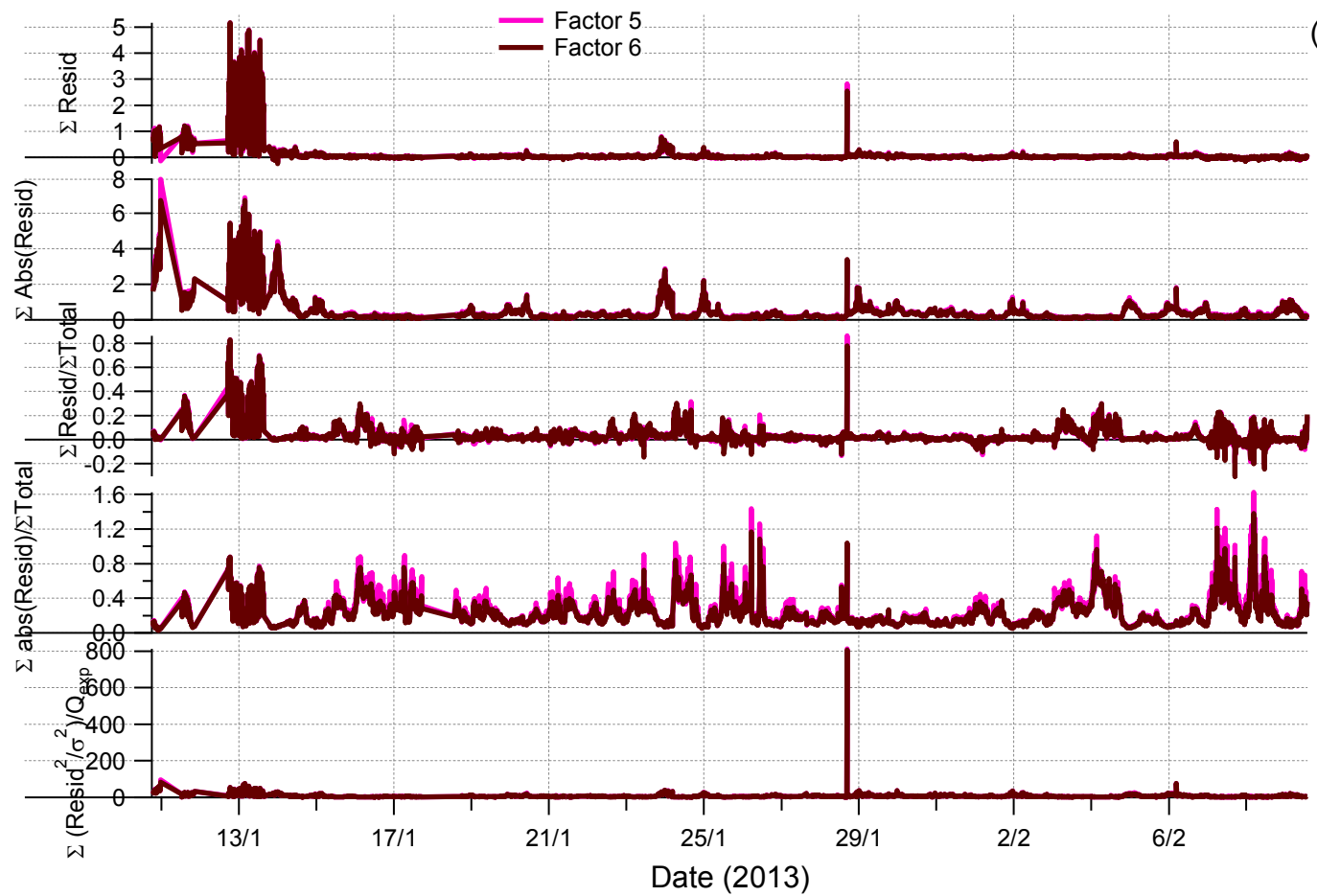

Figure S19. Model residuals $\mathbf{E}=\mathbf{X}-\mathbf{G F}$ calculated using the PMF evaluation tool, PET (Ulbrich et al., 2009) for Athens. Comparison between (d) 4-factor (yellow lines) and 5-factor (pink lines) solutions, and (e) 5-factor (pink lines) and 6-factor (brown lines) PMF solutions. 


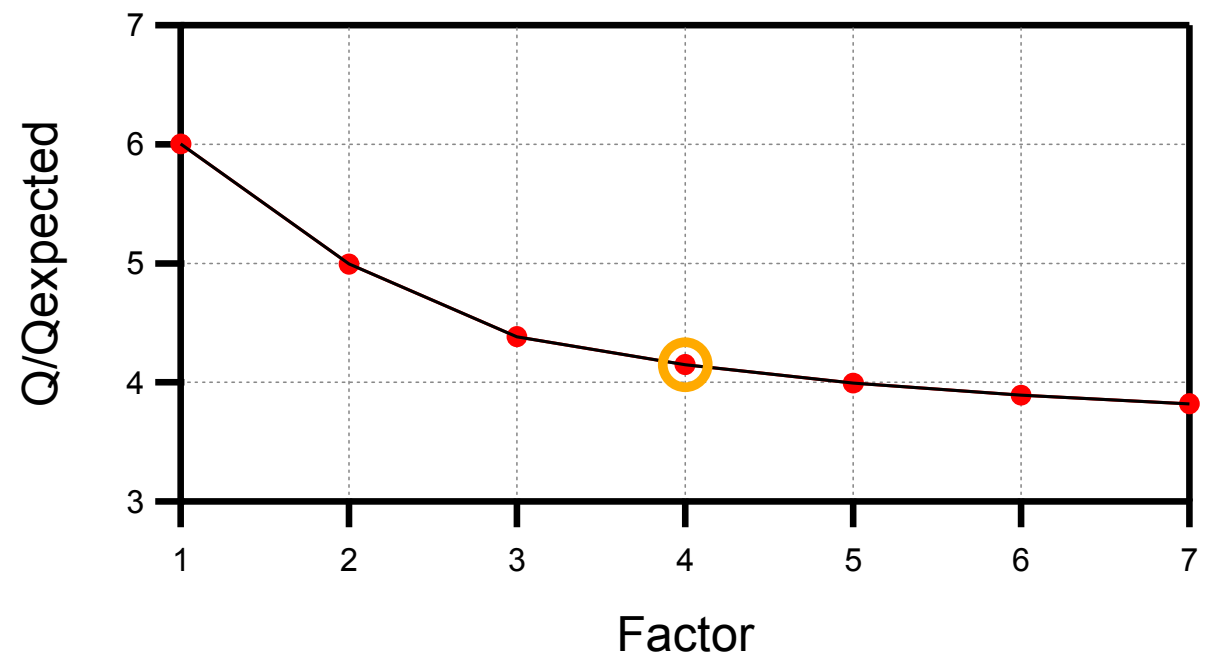

Figure S20. $Q / Q_{\text {expected }}$ Vs. the number of the factors for Athens.

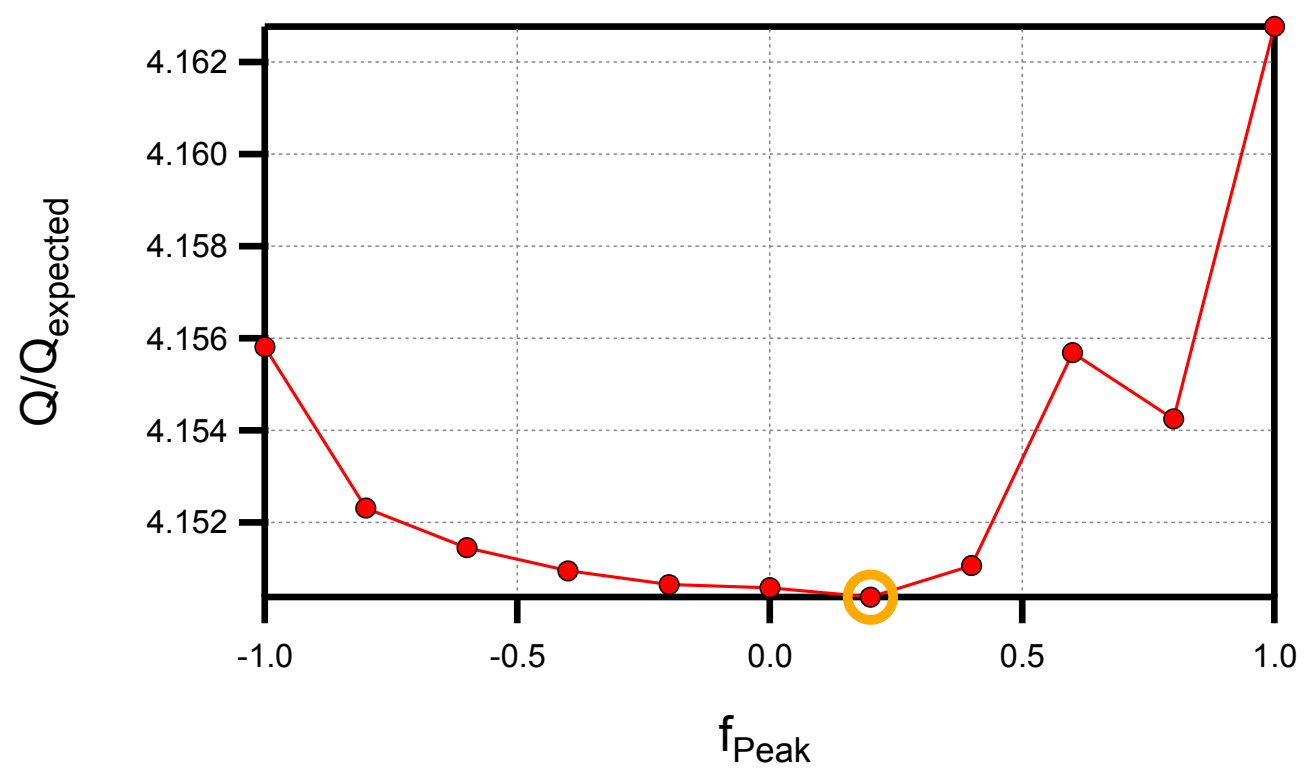

Figure S21. Q/Q $\mathrm{Q}_{\text {expected }}$ for $f_{\text {peak }}-1$ to 1 for a 4 factor solution for Athens. There is a stable area between the $\mathrm{f}_{\text {peak }}-0.4$ and 0.2 , with the lower $\mathrm{Q} / \mathrm{Q}_{\text {expected }}$ at $f_{\text {peak }}=0.2$. 


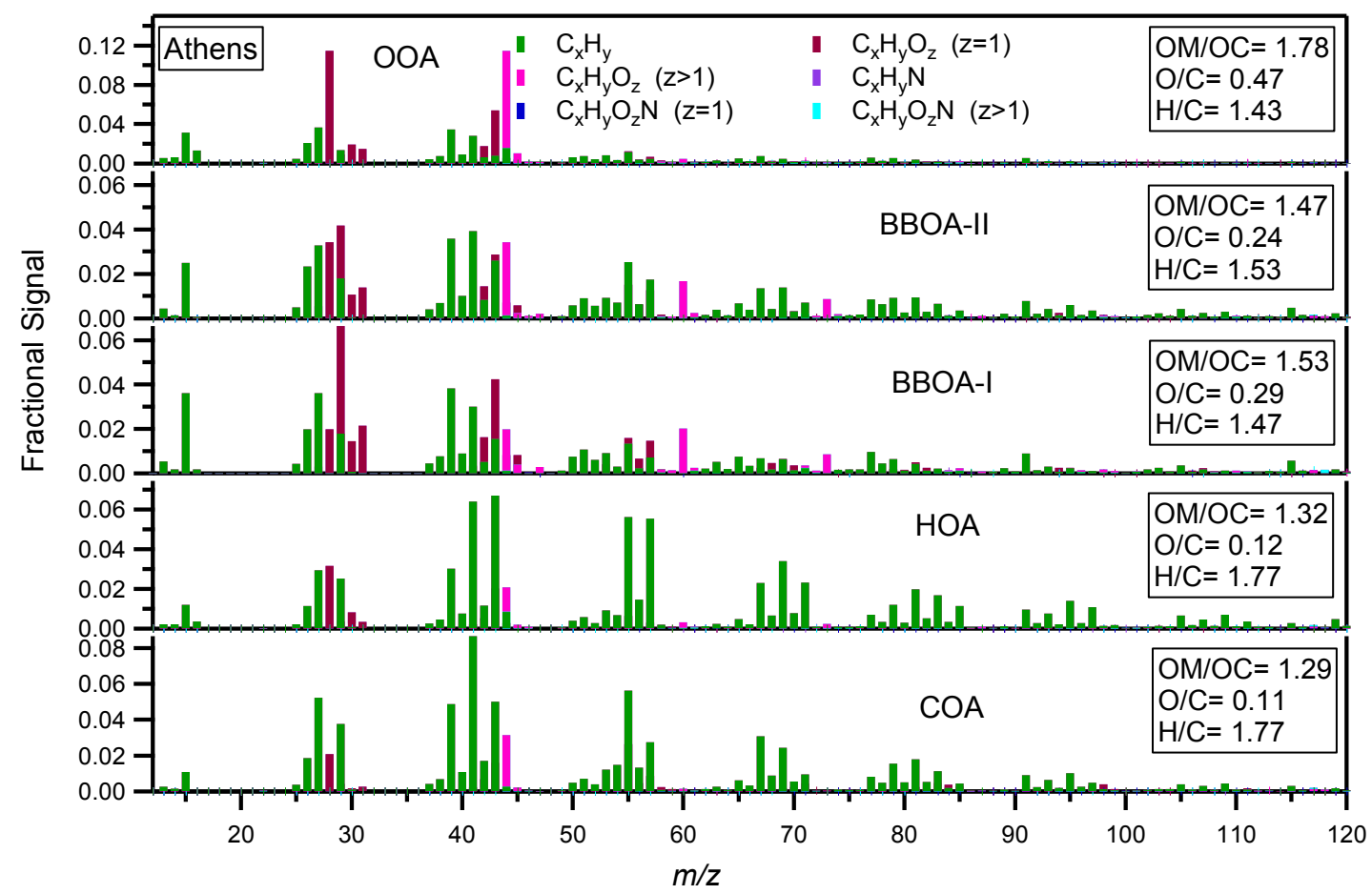

Figure S22. High resolution spectra by the AMS for the 5-factor PMF solution for Athens.

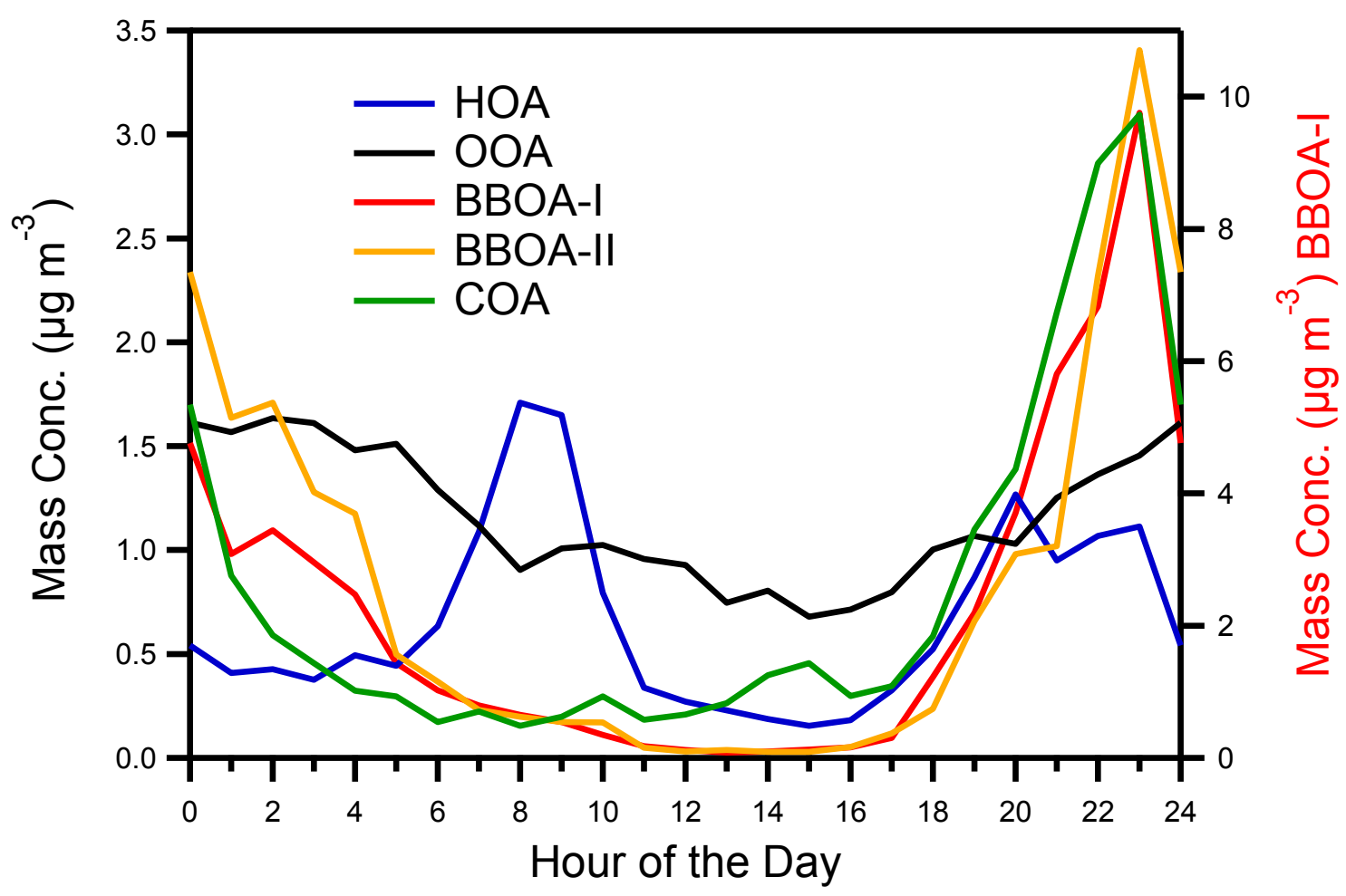

Figure S23. Diurnal profiles of the mass concentration for the 5 factor PMF solution in Athens. The BBOA-I mass concentration appears on the right y-axis. 


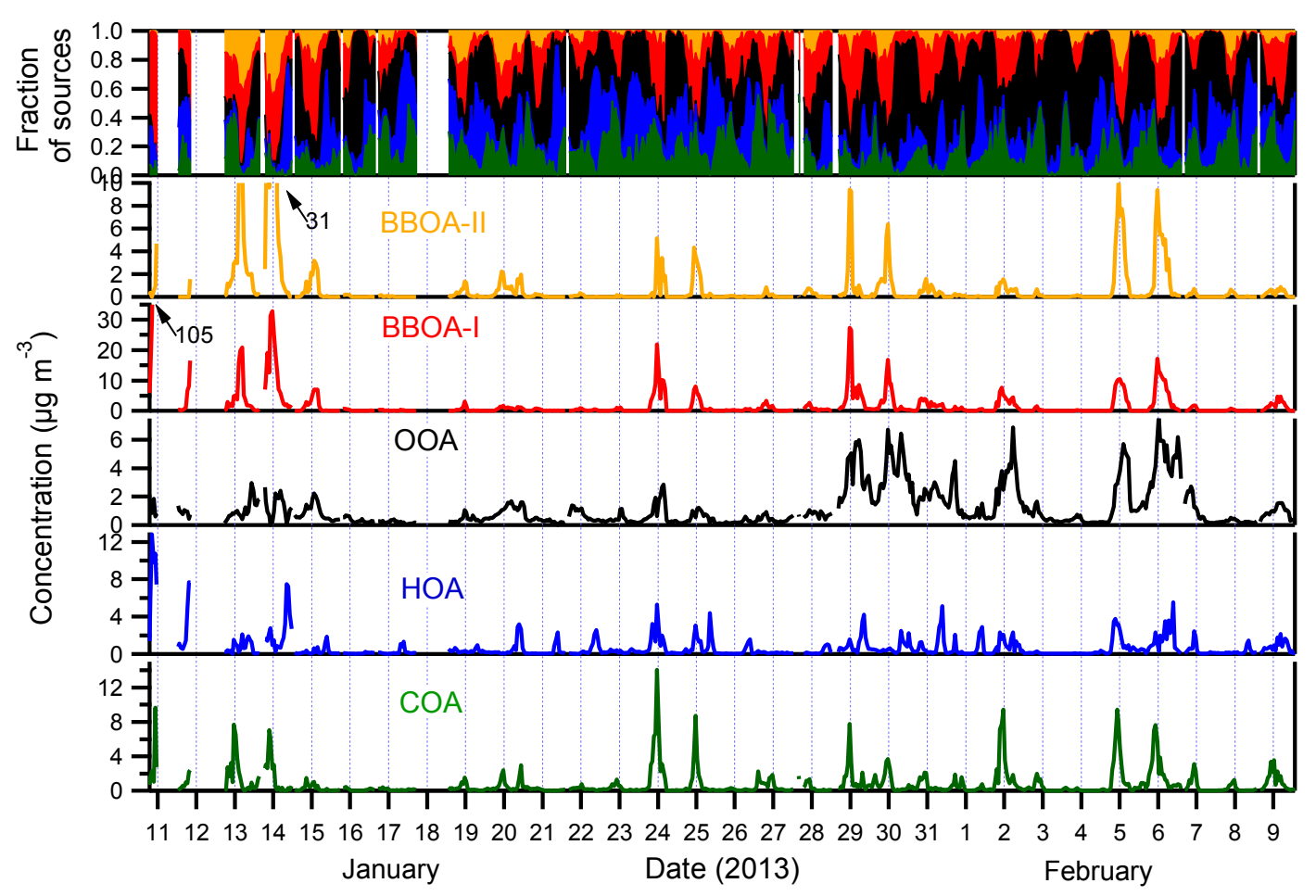

Figure S24. Time series of the 5-factor solution for Athens. The $\mathrm{PM}_{1} \mathrm{OA}$ composition is also shown. During the first day, BBOA-I reached levels up to $105 \mu \mathrm{g} \mathrm{m}^{-3}$ and during the 15 th of January, BBOA-II was equal to $31 \mu \mathrm{g} \mathrm{m}^{-3}$. 
Table S1. Correlation between the 5 factors in Athens and VOCs as measured by the PTRMS.

\begin{tabular}{|c|c|c|c|c|c|}
\hline $\mathrm{R}^{2}$ & BBOA-II & BBOA-I & HOA & $\mathrm{COA}$ & OOA \\
\hline $\mathrm{m} / \mathrm{z} 42$ (Acetonitrile) & 0.43 & 0.74 & 0.57 & 0.32 & 0.10 \\
\hline $\mathrm{m} / \mathrm{z} 43$ & 0.43 & 0.63 & 0.53 & 0.28 & 0.09 \\
\hline m/z 47 (formic acid) & 0.26 & 0.39 & 0.50 & 0.10 & 0.02 \\
\hline $\mathrm{m} / \mathrm{z} 59$ (acetone, glyoxal) & 0.39 & 0.64 & 0.57 & 0.28 & 0.15 \\
\hline m/z 61 (acetic acid) & 0.39 & 0.41 & 0.27 & 0.16 & 0.07 \\
\hline m/z 69 (isoprene, furan) & 0.50 & 0.79 & 0.42 & 0.28 & 0.06 \\
\hline m/z 71 (MVK, MACR) & 0.40 & 0.78 & 0.59 & 0.29 & 0.06 \\
\hline $\mathrm{m} / \mathrm{z} 73(\mathrm{MEK})$ & 0.42 & 0.68 & 0.51 & 0.28 & 0.12 \\
\hline m/z 75 (hydroxyacetone) & 0.41 & 0.60 & 0.22 & 0.21 & 0.03 \\
\hline $\mathrm{m} / \mathrm{z} 79$ (benzene) & 0.34 & 0.68 & 0.65 & 0.28 & 0.08 \\
\hline $\mathrm{m} / \mathrm{z} 81$ (terpenes) & 0.51 & 0.75 & 0.46 & 0.27 & 0.06 \\
\hline $\mathrm{m} / \mathrm{z} 85(\mathrm{EVK})$ & 0.49 & 0.83 & 0.46 & 0.31 & 0.06 \\
\hline $\mathrm{m} / \mathrm{z} 87$ (MBO, C5, methacrylic acid) & 0.55 & 0.83 & 0.33 & 0.30 & 0.07 \\
\hline $\mathrm{m} / \mathrm{z} 93$ (toluene) & 0.15 & 0.39 & 0.66 & 0.17 & 0.05 \\
\hline $\mathrm{m} / \mathrm{z} 95$ (2 vinyl furan, phenol) & 0.22 & 0.42 & 0.21 & 0.11 & 0.00 \\
\hline $\mathrm{m} / \mathrm{z} 99$ (hexenal) & 0.52 & 0.76 & 0.39 & 0.31 & 0.10 \\
\hline $\mathrm{m} / \mathrm{z} 101$ (isoprene hyperoxides) & 0.39 & 0.64 & 0.28 & 0.22 & 0.06 \\
\hline $\mathrm{m} / \mathrm{z} 105$ (styrene) & 0.25 & 0.53 & 0.48 & 0.17 & 0.05 \\
\hline m/z 107 (xylenes) & 0.19 & 0.48 & 0.77 & 0.21 & 0.06 \\
\hline $\mathrm{m} / \mathrm{z} 113$ (chlorobenzene) & 0.51 & 0.69 & 0.37 & 0.28 & 0.11 \\
\hline m/z 115 (heptanal) & 0.38 & 0.60 & 0.32 & 0.20 & 0.06 \\
\hline m/z 121 (C9 aromatics) & 0.20 & 0.48 & 0.76 & 0.20 & 0.06 \\
\hline m/z 129 (octanal, naphthalene) & 0.30 & 0.72 & 0.51 & 0.19 & 0.04 \\
\hline $\mathrm{m} / \mathrm{z} 135$ (C10 aromatics) & 0.23 & 0.50 & 0.71 & 0.20 & 0.07 \\
\hline m/z 137 (monoterpenes) & 0.48 & 0.60 & 0.45 & 0.23 & 0.09 \\
\hline m/z 139 (nopinone) & 0.50 & 0.54 & 0.31 & 0.20 & 0.08 \\
\hline m/z 151 (pinonaldehyde) & 0.21 & 0.28 & 0.21 & 0.08 & 0.02 \\
\hline $\mathrm{m} / \mathrm{z} 163$ (C12 aromatics) & 0.33 & 0.28 & 0.29 & 0.09 & 0.05 \\
\hline
\end{tabular}


7. Comparison of BBOA and $\mathrm{K}^{+}$in Athens

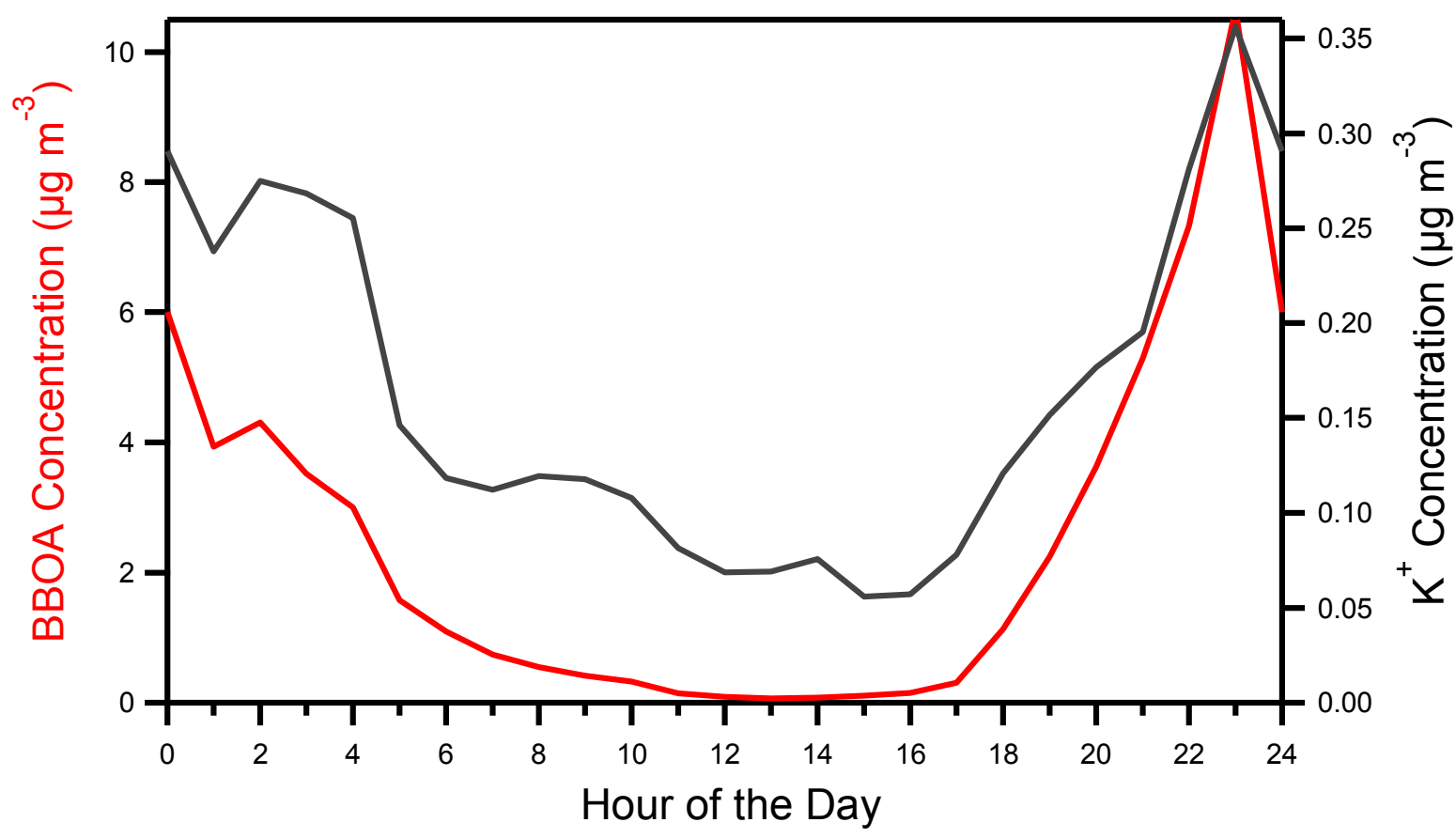

Figure S25. The diurnal profiles of the BBOA (red) and $\mathrm{K}^{+}$(grey) in Athens. 
8. Comparison of the PMF factors' spectra for the two cities
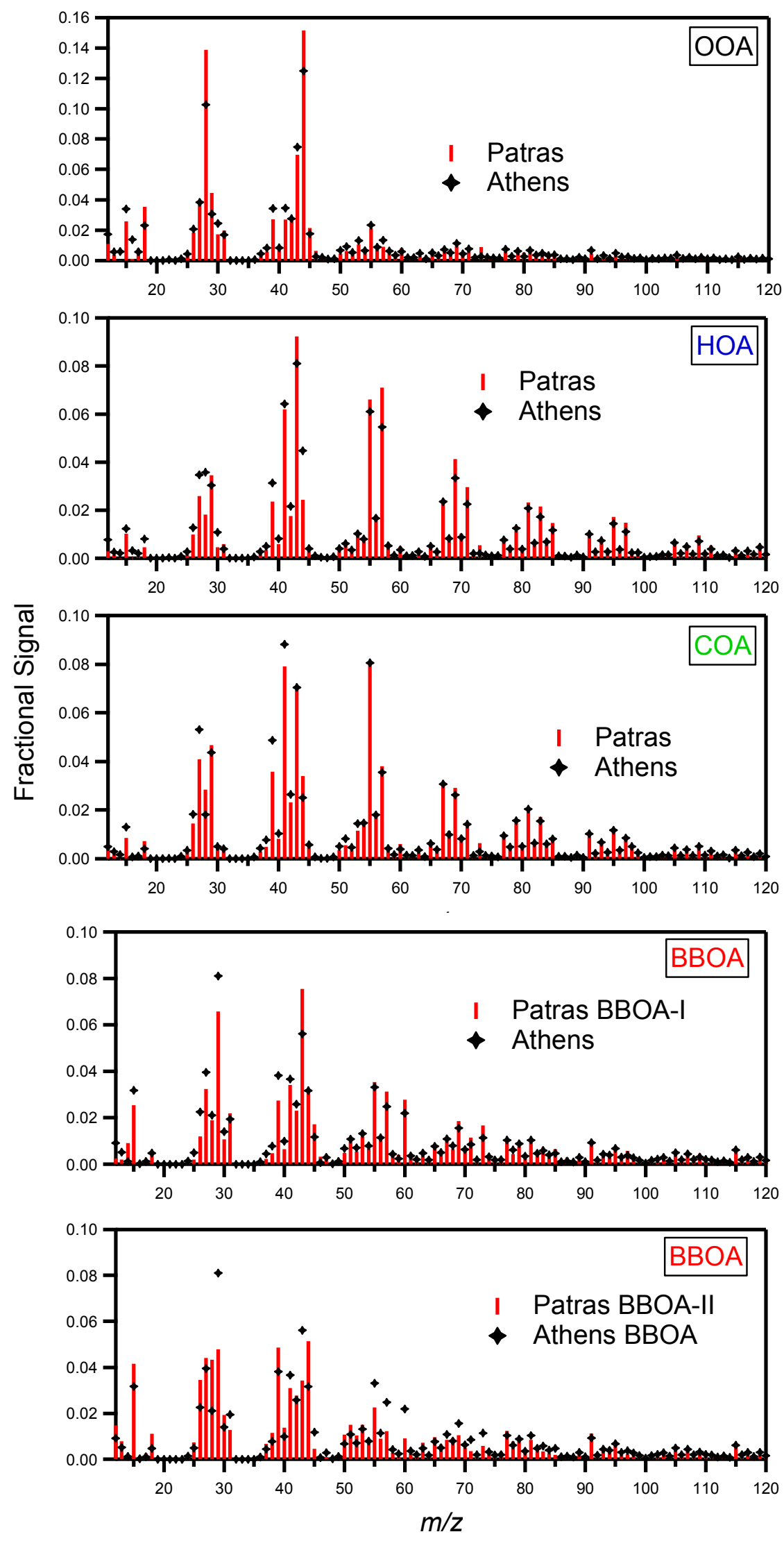

Figure S26. Comparison of the PMF-factor mass spectra for the two cities. 


\section{Comparison of factor spectra with other studies}

\section{BBOA-I Patras}

Beech Smoldering, weimer et al., 2008

Fir Smoldering, Weimer et al., 2008

Oak Smoldering, Weimer et al., 2008

Ricestraw, FLAME-I

Utah Sage Rabbitbrush, FLAME-I

Larch Smoldering, Weimer et al., 2008

Beech, Scneider et al., 2006

Levoglucosan, Scneider et al., 2011

Wood Burning, Lanz et al., 2007

Levoglucosan, Scneider et al., 2006

Brushfire, Bahreini et al., 2005 Utah Juniper, FLAME-I

Chestnut Flaming, Weimer et al., 2008

Palmetto Leaves, FLAME-I Manzanita, FLAME-I

OOA-BBOA, Crippa et al., 2013

OOABB, Bougiatioti et al., 2014

Southern Chamise, FLAME-I

Larch Flaming, Weimer et al., 2008

Fir Flaming, Weimer et al., 2008

Chestnut Smoldering, Weimer et al., 2008

Oak Flaming, Weimer et al., 2008

BBOA-II Patras

Beech Flaming, Weimer et al., 2008

Wood Burning, Lanz et al., 2008

BBOA PoVal, Saarikoski et al., 2013

Ceanothus, FLAME-I

BBOA, Crippa et al., 2013

BBOA DAURE, Mohr et al., 2012

PR Mixed Wood, FLAME-I

Southern Pine Needles, FLAMF-I

Nusasa, Scneider et al., 2006

Ponderosa Pine, FLAME-I

Oak, Scneider et al., 2006

$\mathrm{BBOA}, \mathrm{Ng}$ et al., 2011

Spruce, Scneider et al., 2006

Ponderosa Pine Duff, FLAME-I

Alaska Core Tundra Duff, FLAME-I

Savannah Grass, Scneider et al., 2006

BBOA MILAGRO, Aiken et al., 2009

BBOA Athens

BBOA Fresno, Ge at al., 2012

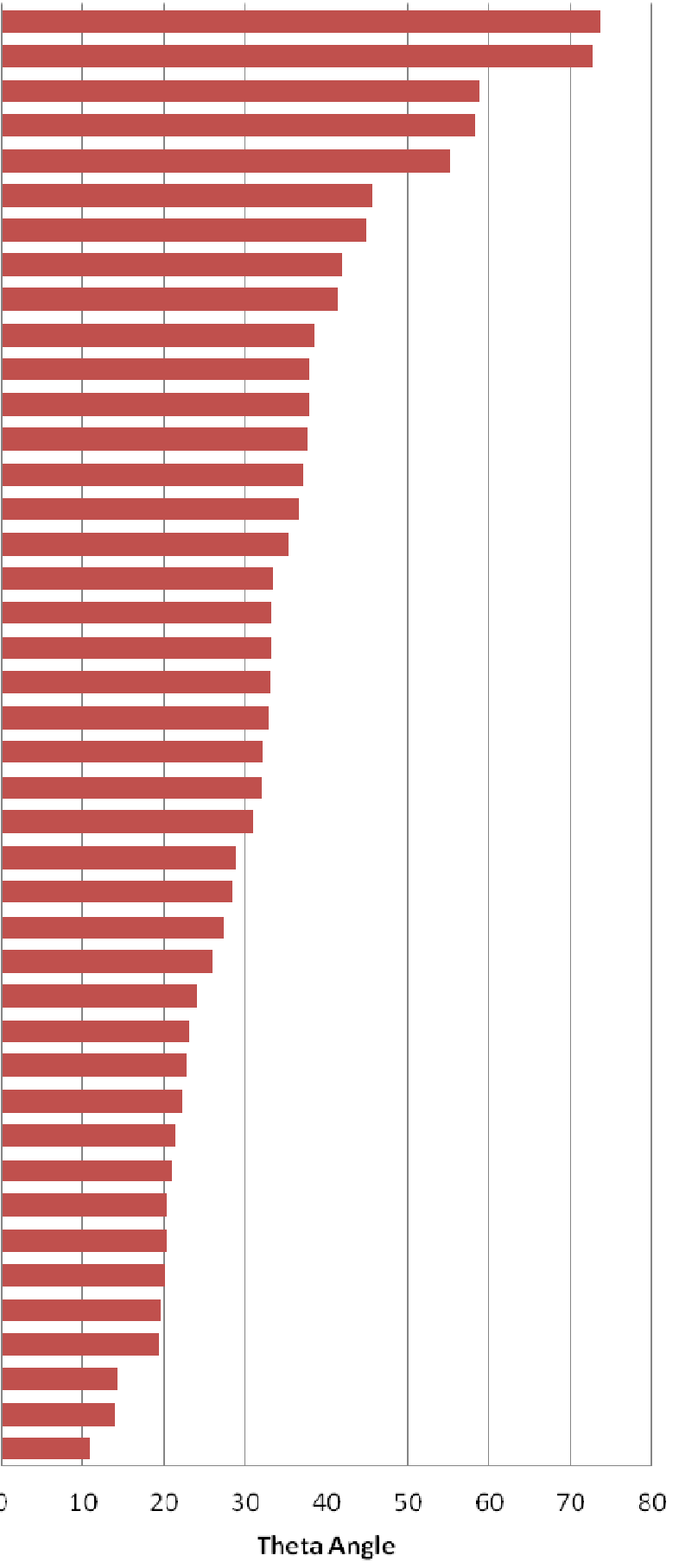

Figure S27. Theta angles between the BBOA-I mass spectra in Patras and BBOA from the literature. 


\section{BBOA-II Patras}

Beech Smoldering, weimer et al., 2008

Fir Smoldering, Weimer et al., 2008

Dak Smoldering, Weimer et al., 2008

Ricestraw, FLAMIE-I

Beech, Scneider et al., 2006

Larch Smoldering, Weimer et al., 2008

Utah Sage Rabbitbrush, FLAMIE-I

Levoglucosan, Scneider et al., 2011

Levog ucosan, Scneider et al., 2006

Spruce, Scneider et al., 2006

Beech Flaming, Weimer et al., 2008

BBOA DAURE, Mlohr et al., 2012

Musasa, Scneider et al., 2006

Wood Burning, Lanz et al., 2007

Savannah Grass, Scneider et al., 2006

Fir Flaming, Weimer et al., 2008

Chestnut Flaming, Weimer et al., 2008

Oak, Scneider et al., 2006

Brushfire, Bahreini et al., 2005

Ponderosa Pine, FLAME-I

Wood Burning, Lanz et al., 2008

Chestnut Smoldering, Weimer et al., 2008

Larch Flaming, Weimer et al., 2008

BBOA, Ng et al., 2011

Oak Flaming, Weimer et al., 2008

Alaska Core Tundra Duff, FLAME-I

Palmetto Leaves, FLAME-I

Utah Juniper, FLAME-I

Southern Chamise, FLAME-I

BBOA, Crippa et al., 2013

Manzanita, FLAME-I

Southern Pine Needles, FLAMIE-I

Ponderosa Pine Duff, FLAME-I

BBOA PoVal, Saarikoski et al., 2013

Ceanothus, FLAME-I

PR Mixed Wood, FLAME-I

BBOA MILAGRO, Aiken et al., 2009

BBOA -I Patras

OOABB, Bougiatioti et al., 2014

BBOA Fresno, Ge at al., 2012

OOA-BBOA, Crippa et al., 2013

BBOA Athens

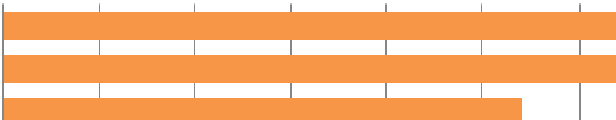

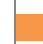
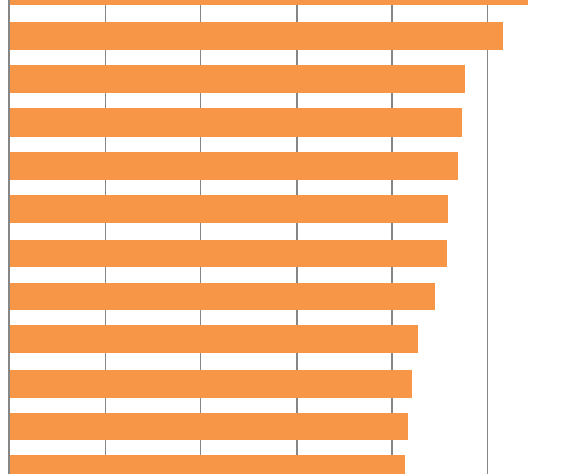

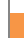

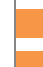

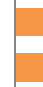

$$
\square
$$

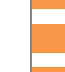

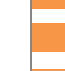

$$
\begin{array}{|l}
\square \\
\square
\end{array}
$$

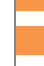

$$
\square
$$

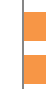

$$
\square
$$

$$
\square
$$

$$
\square
$$

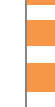

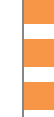

.

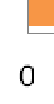

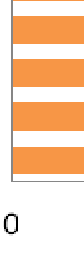




\section{BBOA-II Patras}

OOA RLPARTC[-2, Allan et al., 2010 V-OOA PAT, Kostenidou et al., 2015 OOA REPARTEE-1, Allan et al., 2010 V-OOA ATH, Kostenidou et al., 2015 LV-OOA SOAR, Doherty et al., 2011 OOAa PoVal, Saarikoski et al., 2012 LV-OOA MILAGRO, Aiken et al., 2009 OOA Manchester, Allan et al., 2010 LV-OOA DAURE, Mohr et al., 2012 M-OOA_PAT, Kostenidou et al., 2015 OOAC PoVal, Saarikoski et al., 2012 OOA Patras

M-OOA_ATII, Kostenidou et al., 2015 OOAb PoVal, Saarikoski et al., 2012 SV-OOA MILAGRO, Aiken et al., 2009 b-OOA PAT, Kostenidou et al., 2015 SV-OOA DAURE, Mohr et al., 2012 OOAAthens SV-OOA SOAR, Doherty et al., 2011 OOA NYC, sun et al., 2011 OOA Fresno, Ge et al., 2012
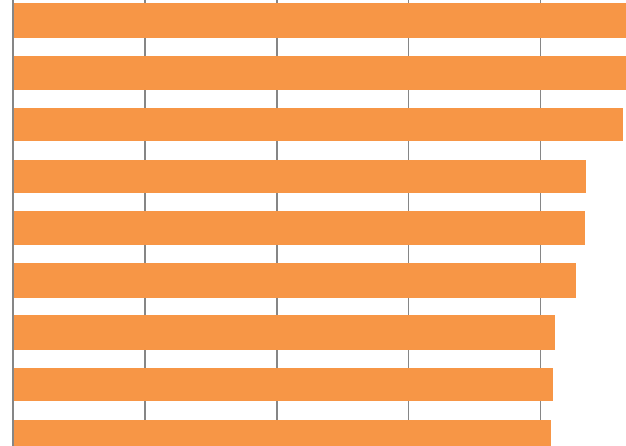

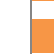

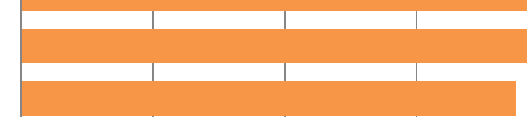

.

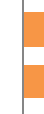
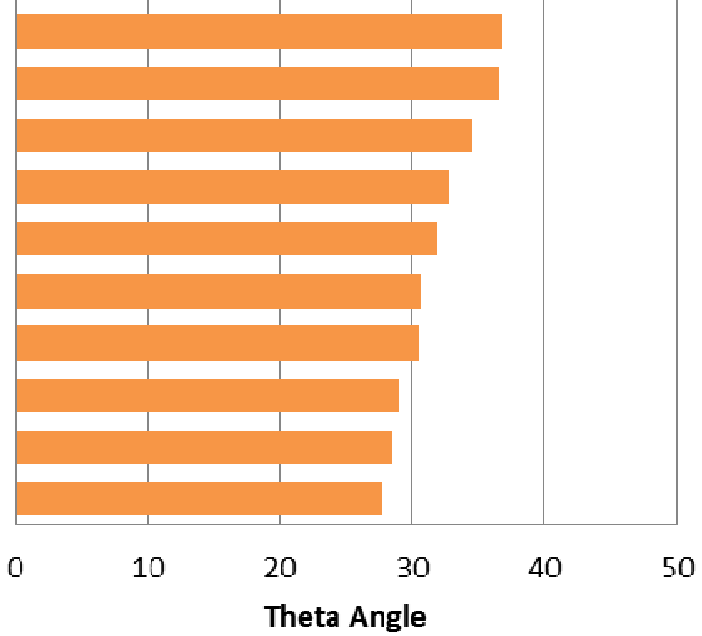

Figure S29. Theta angles between the BBOA-II mass spectra in Patras and OOA from the literature. 


\section{BBOA Athens}

Beech Smoldering, Weimer et al., 2008

Fir Smoldering, Weimer et al., 2008

Oak Smoldering, Weimer et al., 2008 Ricestraw, FLAME-I

Utah Sage Rabbitbrush, FLAME-I Larch Smoldering, Weimer et al., 2008

Beech, Screider et al., 2006

Levoglucosan, Scneider et al., 2011

Chestnut Flaming, Weimer et al., 2008

Brushfire, Bahreini et al., 2005

Utah Juniper, FLAME-I

Manzanita, FLAME-I

Palmetto Leaves, FLAME-I

Wood Burning, Lanz et al., 2007

Beech Flaming, Weimer et al., 2008

Fir Flaming, Weimer et al., 2008

Levoglucosan, Scneider et al., 2006

Southern Chamise, FLAMIE-I

Larch Flaming, Weimer et al., 2008

BBOA DAURE, Mohr et al., 2012

OOA-BBOA, Crippa et al., 2013

OOABB, Bougiatioti et al., 2014

Chestnut Smoldering, Weimer et al., 2008

OakFlaming, Weimer et al., 2008

Ceanothus, FLAME-I

Spruce, Scneider et al., 2006

Musasa, Scneider et al., 2006

Wood Burning, Lanz et al., 2008

Oak, Scneider et al., 2006

Ponderosa Pine, FLAME-I

Savannah Grass, Scneider et al., 2006 BBOA -II Patras

BBOA, Crippa et al., 2013

Southern Pine Needles, FLAME-I BBOA PoVal, Saarikoski et al., 2013

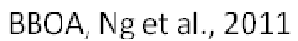

PR Mixed Wood, FLAME-I Alaska Core Tundra Duff, FLAME-I

Ponderosa Pine Duff, FLAME-I

BBOA MILAGRO, Aiken et al., 2009

BBOA - Patras

BBOA Fresno, Ge at al., 2012

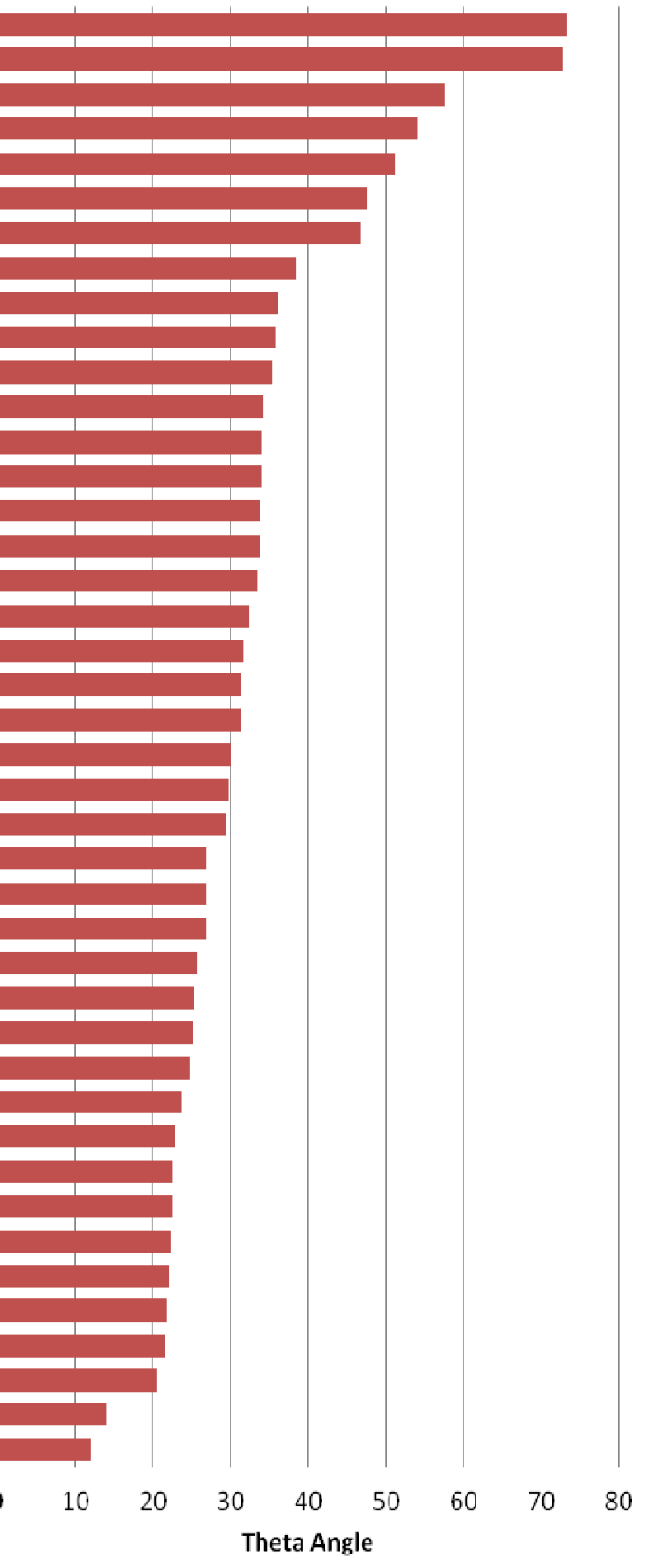

Figure S30. Theta angles between the BBOA mass spectra in Athens and BBOA spectra from the literature. 

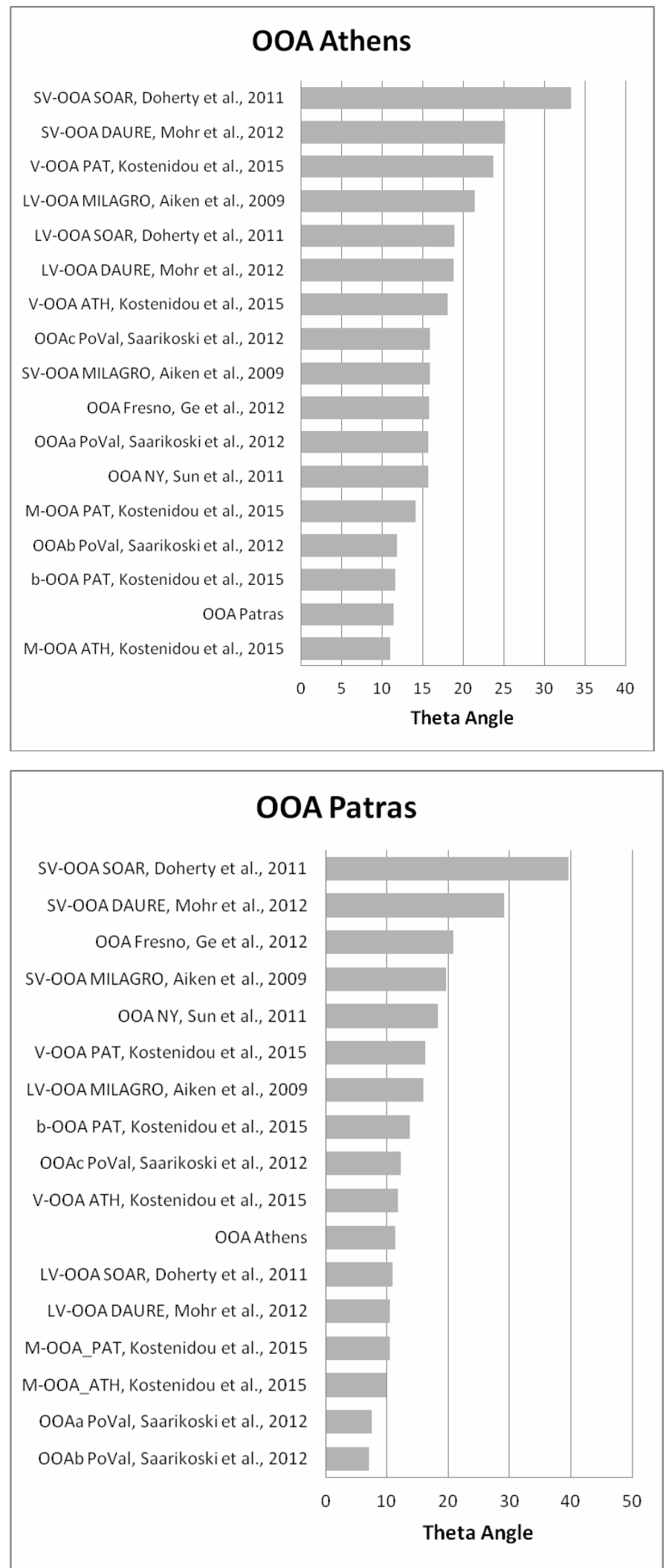

Figure S31. Theta angles between the OOA mass spectra in the two cities and the literature. 


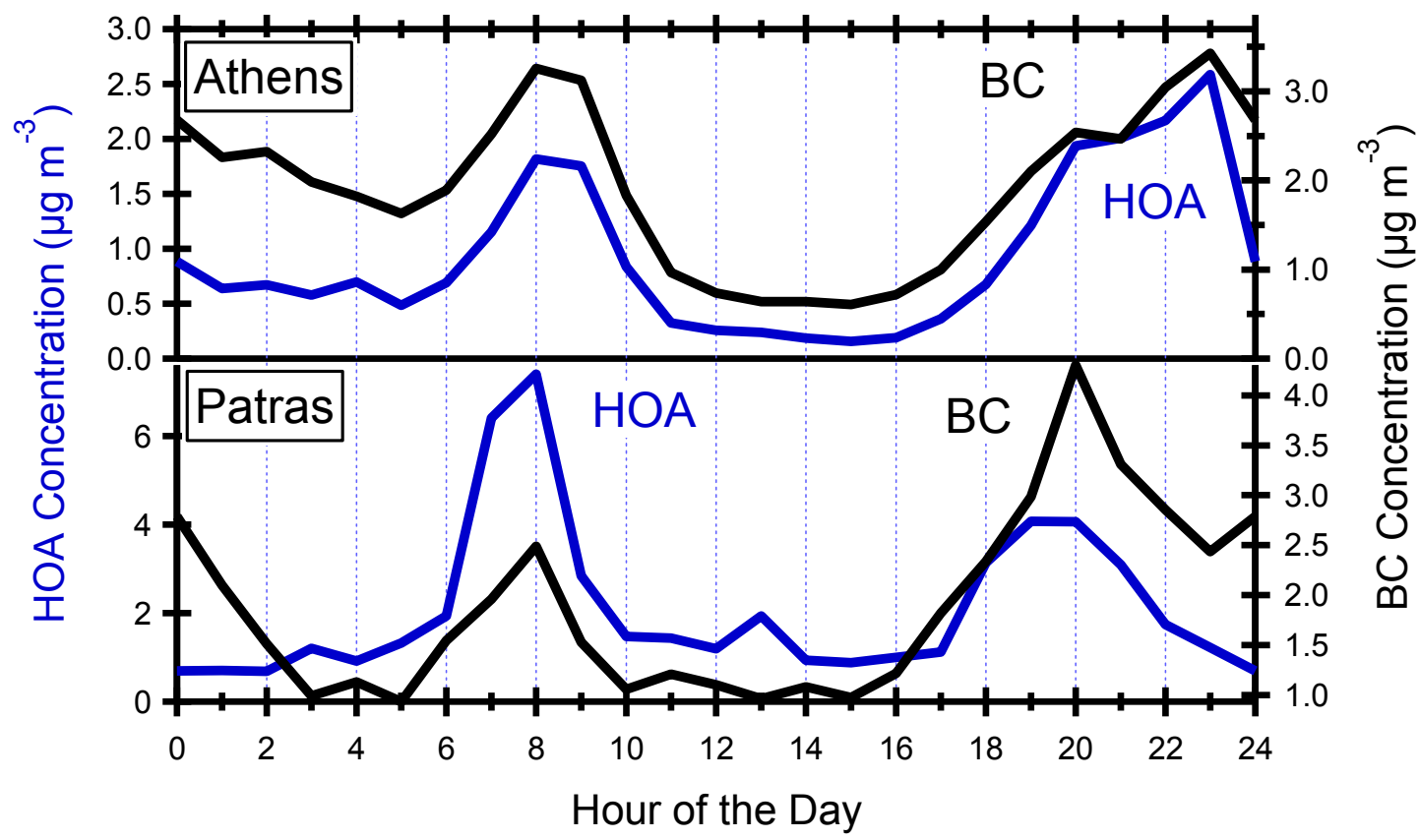

Figure S32. The diurnal profiles of the HOA and $\mathrm{BC}$ in a) Athens and b) Patras. 

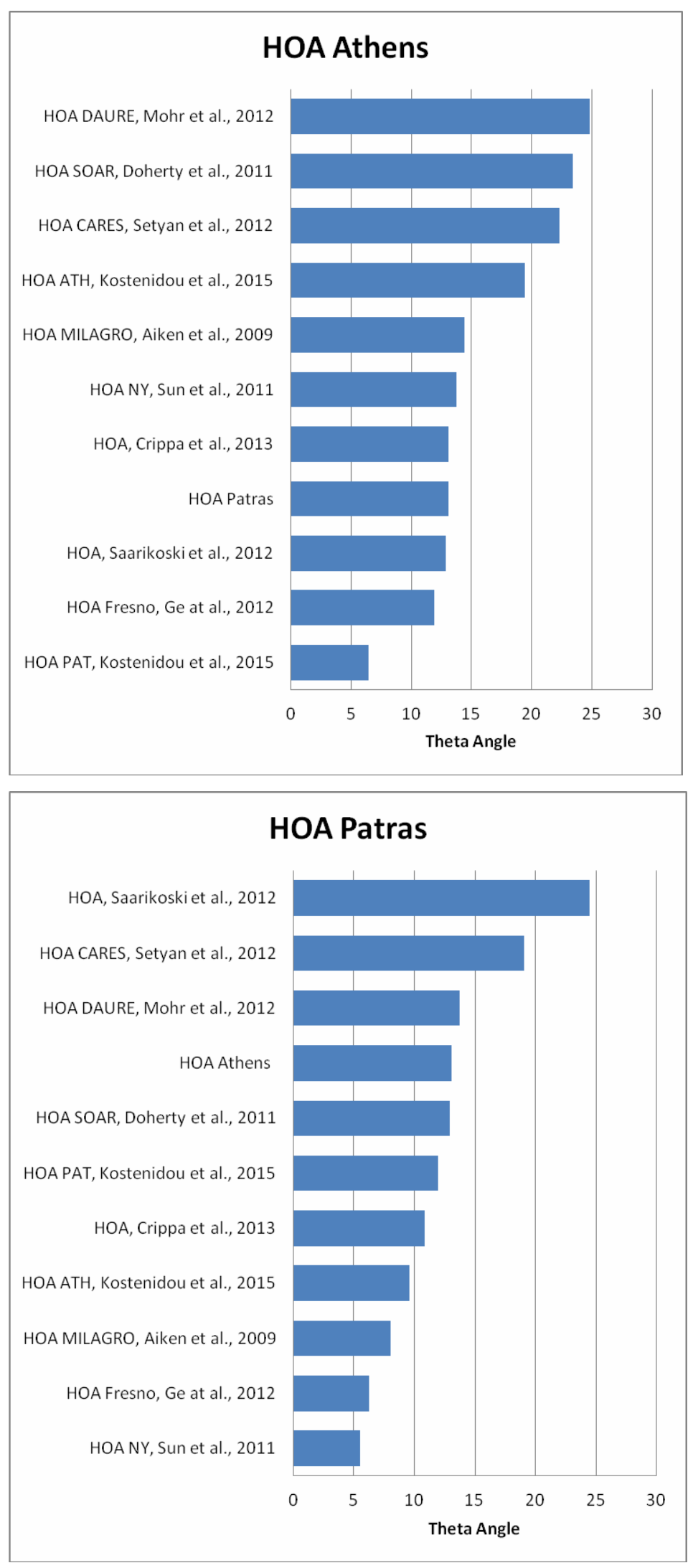

Figure S33. Theta angles between the HOA mass spectra in the two cities and the literature. 

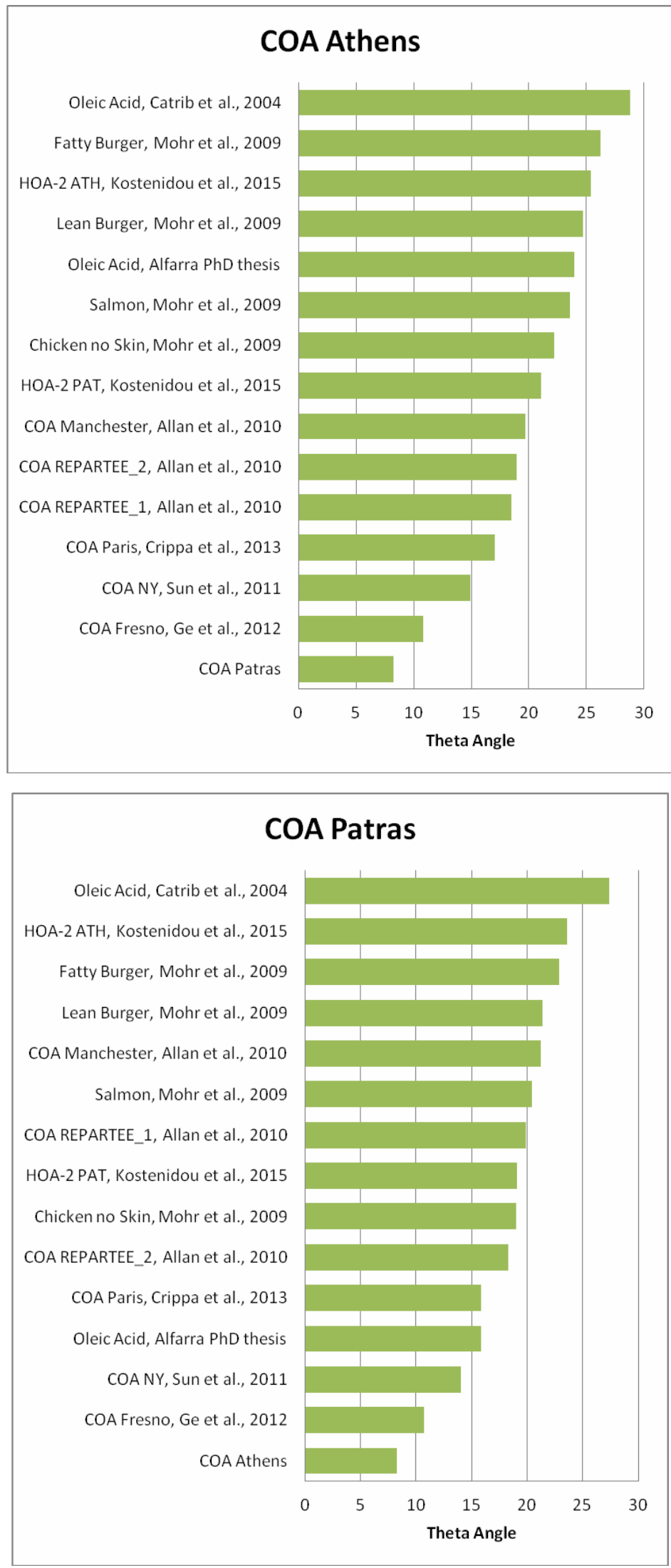

Figure S34. Theta angles between the COA mass spectra in the two cities and the literature. 
10. Ng Triangles

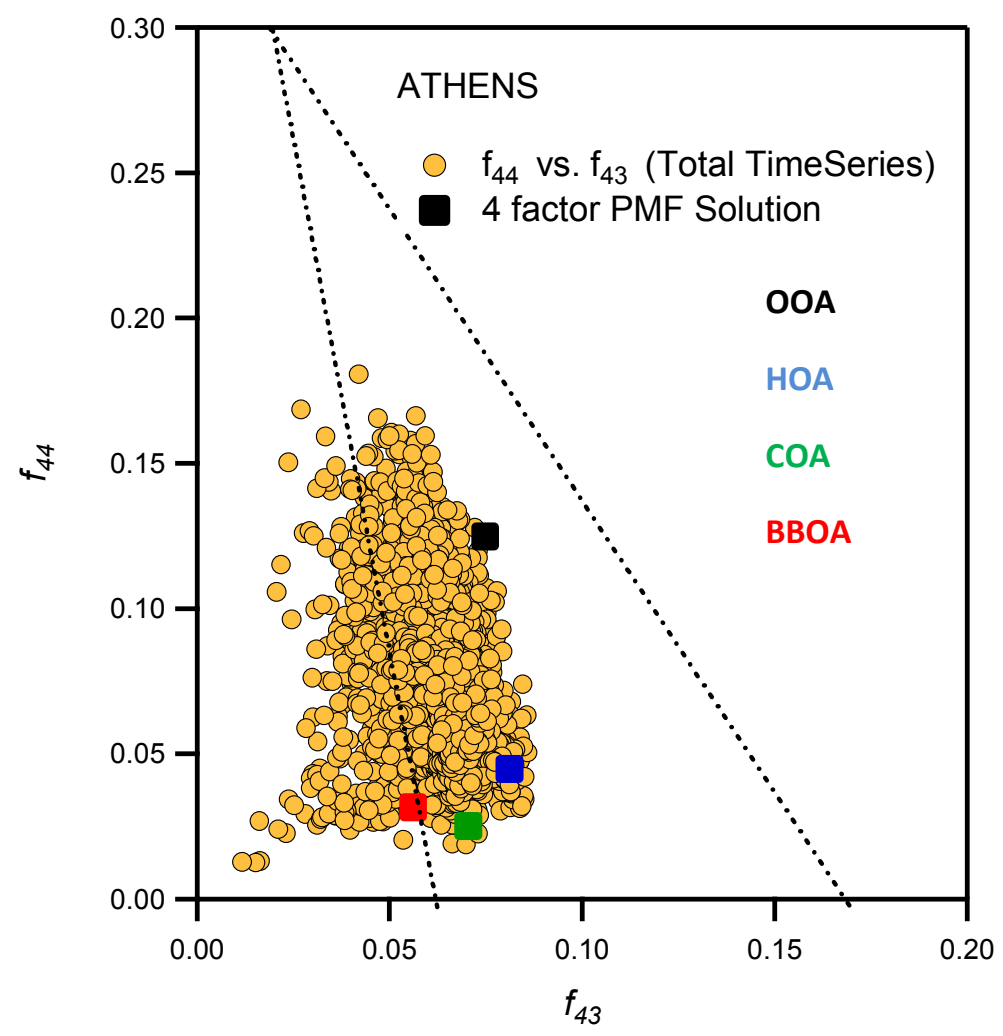

Figure $\mathbf{S 3 5}$. $\mathrm{Ng}$ triangle for the Athens campaign.

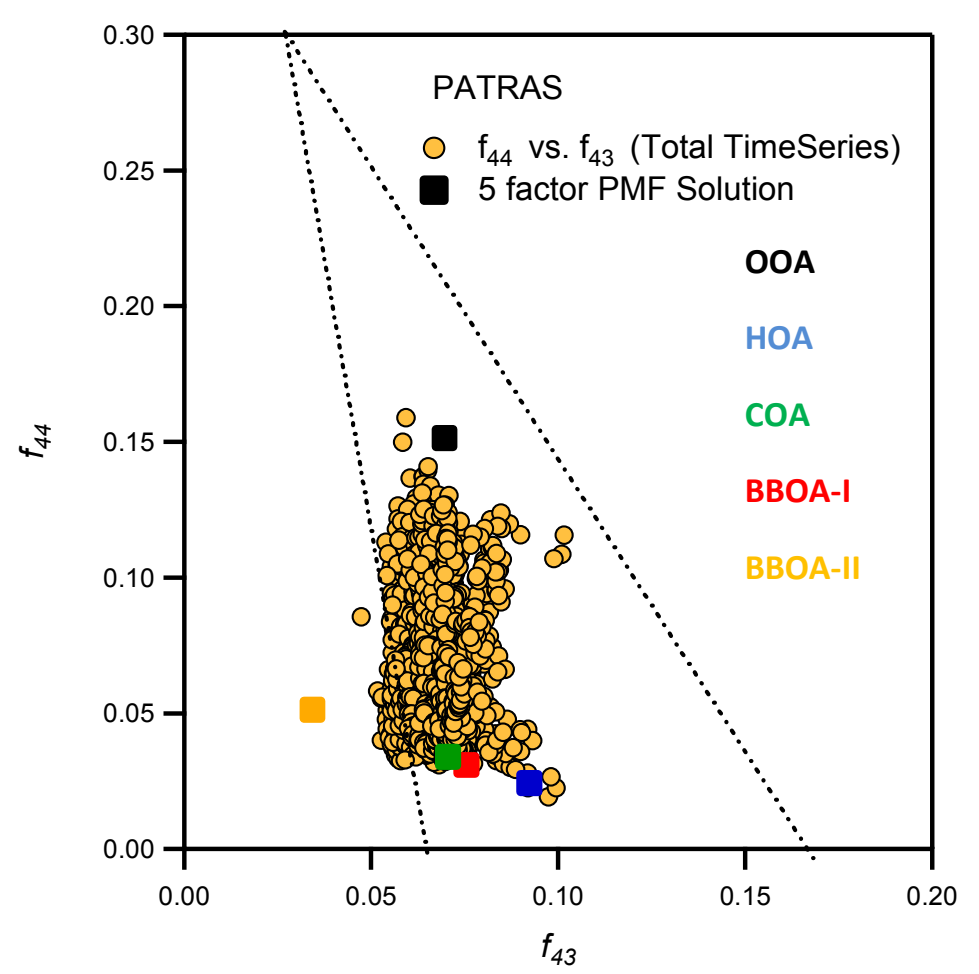

Figure S36. $\mathrm{Ng}$ triangle for the Patras campaign. 